Portland State University

PDXScholar

Summer 8-16-2013

\title{
Emotion Regulation and Strain in Corrections Officers: Examining the Role of Recovery Experiences and Coping Mechanisms
}

Frankie Guros

Portland State University

Follow this and additional works at: https://pdxscholar.library.pdx.edu/open_access_etds

Part of the Criminology and Criminal Justice Commons, Industrial and Organizational Psychology Commons, and the Social Psychology Commons

Let us know how access to this document benefits you.

\section{Recommended Citation}

Guros, Frankie, "Emotion Regulation and Strain in Corrections Officers: Examining the Role of Recovery Experiences and Coping Mechanisms" (2013). Dissertations and Theses. Paper 1121.

https://doi.org/10.15760/etd.1121

This Thesis is brought to you for free and open access. It has been accepted for inclusion in Dissertations and Theses by an authorized administrator of PDXScholar. Please contact us if we can make this document more accessible: pdxscholar@pdx.edu. 
Emotion Regulation and Strain in Corrections Officers: Examining the Role of Recovery Experiences and Coping Mechanisms

by

Frankie Guros

A thesis submitted in partial fulfillment of the requirements for the degree of

\author{
Master of Science \\ in \\ Psychology
}

Thesis Committee:

Charlotte Fritz, Chair

Leslie Hammer

Keith Kaufman

Portland State University

2013 
C2013 Frankie Guros 


\begin{abstract}
Research has begun to identify recovery experiences during nonwork time as an important mechanism explaining the relationship between job characteristics and strain (Geurts \& Sonnentag, 2006; Kinnunen, Feldt, Siltaloppi, Sonnentag, 2011). Corrections officers face challenges unique to their occupation (Armstrong \& Griffin, 2004) that may contribute to the high levels of strain that currently characterize their occupation (i.e., short life expectancy, high suicide rates; Spinaris \& Denhof, 2011; Stack \& Tsoudis, 1997). Though previous research has not examined emotion regulation, recovery experiences, and coping within corrections officers, these constructs may be of particular importance to an occupation that requires employees to navigate the complex demands of managing an incarcerated population of individuals. Emotion regulation - managing one's emotions - is an important aspect of many jobs, and has been linked with employee strain, such as burnout, psychological strain, and psychosomatic complaints (Hülsheger $\&$ Schewe, 2011). However, research only begun to assess nonwork recovery and its relationship with emotion regulation strategies at work, and additionally the influence of individual coping strategies has not been considered in past studies. I offered that recovery experiences (i.e., psychological detachment, relaxation, and mastery) mediated the relationship between emotion regulation at work (i.e., reappraisal and suppression) and strain (i.e., disengagement, emotional exhaustion, and psychological distress). I further offered, based on the matching hypothesis (de Jonge \& Dormann, 2006), that emotion-focused coping strategies (i.e., emotional social support and venting emotions) moderated the relationships between emotion regulation, recovery experiences, and
\end{abstract}


strain. To examine these hypotheses, data were collected via a survey of corrections officers in Oregon $(\mathrm{N}=1317)$. Results indicated that emotion regulation at work was associated with strain, and this relationship was partially mediated by recovery experiences. The results further suggested that the coping strategies examined in this study did not appear to moderate relationships between the study variables. These findings are discussed in the context of the present sample, and implications for future research are considered. 
Table of Contents

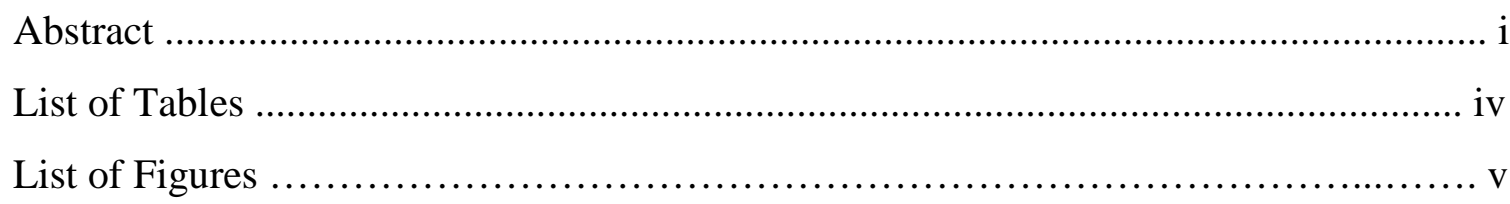

\section{Chapter 1}

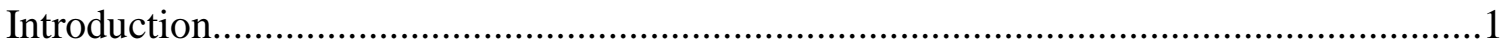

Chapter 2

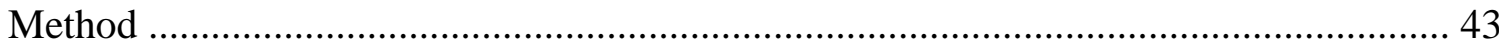

Chapter 3

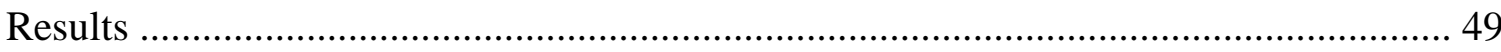

Chapter 4

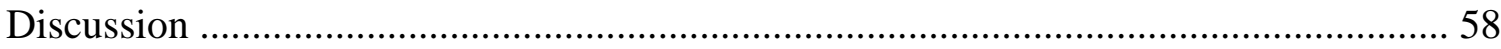

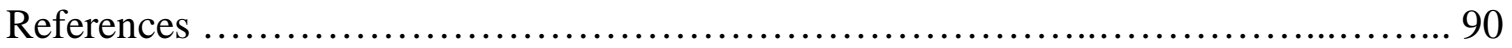

Appendix

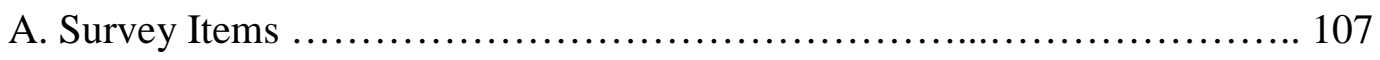

B. Email of Support: Union Representative I .......................... 111

C. Email of Support: Union Representative II ......................... 112

D. Survey Recruitment Email: Assistant Director of Operations .............. 113

E. Templates for Email Support For Superintendents .................... 115

F. First Reminder Email ............................................ 117

G. Second Reminder Email ......................................... 118

H. ODOC-PSU Research Collaboration Agreement ...................... 119

I. Corrections Officer and Inmate Population by Facility ................... 120

J. Means of Study Variables by Facility ............................... 121 


\section{List of Tables}

Table 1

Means, Standard Deviations, and Zero-Order Correlations of Study Variables

Table 2

Hierarchical Multiple Regression Analyses Predicting Strain From Reappraisal 78

Table 3

Hierarchical Multiple Regression Analyses Predicting Strain From Suppression 79

Table 4

Hierarchical Multiple Regression Analyses Predicting Recovery Experiences From Reappraisal .......................................................... 80

Table 5

Hierarchical Multiple Regression Analyses Predicting Recovery Experiences From Suppression .......................................................... 81

Table 6

Hierarchical Multiple Regression Analyses Predicting Strain From Psychological Detachment ................................................................. 82

Table 7

Hierarchical Multiple Regression Analyses Predicting Strain From Relaxation

Table 8

Hierarchical Multiple Regression Analyses Predicting Strain From Mastery 84

Table 9

Summary of Mediation Analyses Using Baron and Kenny’s Criteria 85 


\section{List of Figures}

Figure 1

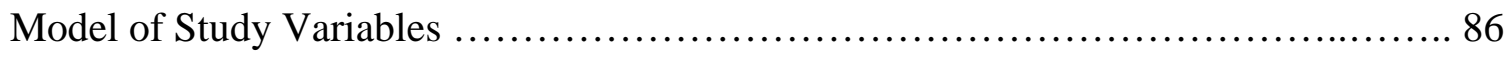

Figure 2

Interaction Between Suppression and Emotional Social Support on Detachment ........ 87

Figure 3

Interaction Between Suppression and Venting on Disengagement .......................... 88

Figure 4

Interaction Between Suppression and Venting on Exhaustion ..................... 89 


\section{Chapter 1 \\ Introduction}

Corrections officers work in an environment unlike any other occupation.

Correctional institutions are charged with the rare task of supervising and detaining an "unwilling and potentially violent population" (Armstrong \& Griffin, 2004, p. 577), and corrections officers are responsible for day-to-day operations required by such an undertaking. Corrections officers have one of the highest on-the-job nonfatal injuries rates. The National Institute for Occupational Safety and Health (NIOSH) estimated that there were 113 fatalities and 125,200 nonfatal injuries requiring treatment in emergency rooms in the occupation between 1999 and 2008. With an estimated 493,100 corrections officers working in the U.S. as of 2011, the effects of working in this occupation reach a great number of individuals (National Occupational Research Agenda (NORA), 2013). The psychological and physical costs associated with work demands can be detrimental to both individual officers as well as the organizations they operate within. Burnout is one such cost: A modest number of studies have identified burnout in corrections as a factor related to organization-wide absenteeism and turnover rates (Griffin, Hogan, Lambert, Tucker-Gail, \& Baker, 2010; Lambert, Hogan, Dial, Jiang, \& Khondaker, 2012; Schaufeli \& Peeters, 2000). Employees high in burnout are characterized by high levels of exhaustion and negative attitudes toward work (Maslach, Schaufeli, \& Leiter, 2001). A growing body of literature has identified numerous consequences of employee burnout across occupations, including reduced commitment, job satisfaction, increased turnover intentions, and physiological symptoms (e.g., Shirom, 2003). 
If left unaddressed, symptoms of burnout may facilitate the development of psychological distress or depressive symptoms (Melamed, Shirom, Toker, Berliner, \& Shapira, 2006), and these outcomes can be associated with great costs to employees and organizations. One study of U.S. employees across a variety of occupations estimated that affective disorders (e.g., depression) were associated with a projected 4 million lost workdays and 20 million work cutback days per year (Kessler \& Frank, 1997). Corrections officers especially may be prone to adverse consequences stemming from burnout and psychological distress. For example, in addition to a reduced average life expectancy and higher suicide rates than other jobs (including police officers), many corrections officers will experience symptoms of post-traumatic stress disorder during their career (Spinaris \& Denhof, 2011; Stack \& Tsoudis, 1997) and as many as $31 \%$ report signs of serious psychological depression (Obidoa, Reeves, Warren, Reisine, \& Cherniack, 2011).

One workplace factor that may contribute to burnout and psychological distress is emotion regulation. In response to the requirements of the job, employees may influence which emotions they have and when and how they experience and express these emotions through emotion regulation (Grandey, 2000; Gross, 1998). It has been suggested that corrections officers must manage their emotions frequently, due to the complex characteristics of the prisoners they must control and through typical workplace interactions with their coworkers and supervisors (Nylander, Lindberg, \& Bruhn, 2011). Though many studies have examined emotion regulation in organizations, it has recently been suggested that researchers should focus their measurement on specific strategies of 
emotion regulation, rather than traditional global measures (Hülsheger \& Schewe, 2011). The dominating paradigm for studying emotion regulation in organizations has been a focus on service encounters (Grandey, 2000) and use of theories of emotional labor to measure the type of acting that service employees utilize (Hochschild, 1983). However, recent research has shown that employees engage in a variety of emotion regulation strategies (as many as 14 strategies; Diefendorff, Richard, \& Yang, 2008) across various work situations (Diefendorff et al., 2008). For instance, interactions with one's supervisor can be related to strain (Bono, Foldes, Vinson, \& Muros, 2007). Still, studies that measure specific emotion regulation strategies in the workplace are rare, and none so far have integrated literature on recovery experiences, coping strategies, and employee strain while examining emotion regulation.

One major factor that could be contributing to the strain symptoms of corrections officers is their inability to recover from work demands. Recovery experiences, or disengaging from work demands and engaging in nonwork activities (Sonnentag \& Fritz, 2007), may provide corrections officers with the opportunity to let their internal systems recover from the work demands that accumulate during the work day and to replenish resources that may have been expended (Hobfoll, 1989; Meijman \& Mulder, 1998). A growing body of literature has begun to elucidate the importance of certain recovery experiences from work and their relationship with reduced burnout symptoms (e.g., Fritz \& Sonnentag, 2006; Kühnel \& Sonnentag, 2011; Sonnentag \& Fritz, 2007). Recovery during nonwork may be especially relevant in the corrections occupation, as the complex relationships that corrections officers balance at work may require them to engage in a 
variety of emotion regulation strategies that tax regulatory resources (Nylander et al., 2011). However, literature on recovery experiences has yet to examine the link between stressors at work such as emotion regulation and recovery.

Another factor that may influence correction officer strain may be how they generally appraise and address stressful situations, or the type of coping strategies they use (Lazarus, 1999). Research has suggested that individuals tend to have fairly stable preferences for the type of coping they use when they experience a situation that they perceive is threatening to their well-being (Carver, Scheier, \& Weintraub, 1989). Coping strategies are related to emotion regulation, but coping may only occur when negative affective reactions arise from a stressful situation (Gross, 1998), and coping strategies are not limited to workplace interactions. The ability of a corrections officer to handle emotional job demands may partially hinge on whether they engage in an emotionfocused coping strategy (de Jonge \& Dormann, 2006). However, research on emotionfocused coping (i.e., coping aimed at reducing or managing emotional distress associated with, or caused by, the situation; Carver et al., 1989; Lazarus \& Folkman, 1984), has produced contradictory evidence of its utility. Though recent research has suggested that emotional support plays a buffering role between emotional job demands and emotional exhaustion (de Ven, van den Tooren, \& Vlerick, 2013), researchers are not certain of whether emotion-focused coping is useful and under what circumstances it can buffer against strain outcomes.

A better understanding is needed for organizations for how different strategies for emotion regulation may be associated with individual employee outcomes. Examining 
this has implications for what workplace stressors organizations should pay close attention to, especially in occupations such as corrections. This study is a first step toward understanding important factors specific to the corrections industry that may offer one avenue for interventions to address and potentially protect employees from strain outcomes (Lawrence, Troth, Jordan, \& Collins, 2011).

The first contribution of this study was to aim to fill a gap in the literature by examining whether emotion regulation is associated with nonwork recovery experiences. Researchers have examined similar constructs (i.e., emotional dissonance; Sonnentag, Kuttler, \& Fritz, 2010) and one specific recovery experience (i.e., psychological detachment), but no study has analyzed the relationships between several emotion regulation strategies and several recovery experiences. Given the different characteristics of recovery experiences and emotion regulation strategies, it is important to understand the potentially complex relationships that may exist and how these relationships may be associated with burnout and psychological distress symptoms.

Since little is known about the connection between recovery experiences, emotion regulation, and coping strategies, the second contribution of this study was to examine the relationships between these factors as correlates of strain within the corrections occupation. The current study proposed that the type of emotion regulation strategies an employee tends to use at work is associated with their nonwork recovery experiences, which in turn are associated with their subjective feelings of strain. Additionally, this study took an exploratory approach to by examining individual strategies for emotionfocused coping and how they affect the magnitude of the relationship between recovery 
and strain. Though several studies have examined strain among correctional officers (e.g., Dollard \& Winefield, 1998), none have explicitly measured the associations between: 1) emotion regulation, 2) recovery experiences, and 3) coping and strain.

A third contribution of this study was to examine two specific strategies of emotion regulation at work: reappraisal (i.e., re-construing a situation to change its emotional impact) and suppression (i.e., inhibiting ongoing emotional response tendencies; Gross, 1998). By examining specific strategies rather than less descriptive global emotion regulation measures, this study aimed to contribute to the ongoing search for an explanation of non-significant relationships between certain types of emotion regulation and strain in the emotional labor literature (Hülsheger \& Schewe, 2011). Figure 1 displays a model of the study variables and the hypothesized relationships.

\section{Emotion Regulation in Organizations}

In today's ever-changing and complex workplace, employees likely encounter situations in which they must manage their emotions to improve results at work. Specifically, employees may need to display different emotions from the ones actually felt (Grandey, 2000; Hochschild, 1983). Below, I outline the emotional labor perspective on emotion regulation, and then discuss gaps in this line of research. I then describe the conceptual process of emotion regulation in detail, and propose that utilizing traditional research on emotion regulation can extend the understanding of how employees deal with their emotions and more accurately predict the outcomes of this process (Mikolajczak, Tran, Brotheridge, \& Gross, 2009). 
Emotional labor. Emotional labor was first introduced by Hochschild (1983) to refer to the management of an individual's emotions for a wage. Hochschild (1983) conceptualized a dichotomy of emotion regulation strategies to describe how employees in service jobs regulate their emotions in the workplace. Deep acting occurs when an individual consciously attempts to modify their feelings in order to express the desired emotion, while surface acting entails an attempt to modify emotional expressions. Typically, an individual is thought to manage their emotions in accordance with specific display rules, or organizational rules for expression of emotions (Ekman \& Friesen, 1975; Hochschild, 1983). Hochschild (1983) suggested that engaging in emotional labor was effortful for employees, and would therefore lead to burnout and job stress (Grandey, 2000). Grandey (2000) developed this perspective further by integrating Hochschild's (1983) framework with other conceptualizations of emotion labor (i.e., Ashforth \& Humphrey, 1993; Morris \& Feldman, 1996). Specifically, Grandey (2000) proposed that deep acting was a form of antecedent-focused emotion regulation, and surface acting was a form of response-focused emotion regulation. Grandey (2000) concluded that deep acting should be more positively related to performance than surface acting based on Gross' (1998) theory that antecedent-focused emotion regulation led to less physiological arousal than response-focused emotion regulation, or surface acting, and that customers would be less likely to detect this type of regulation and would therefore report a better service encounter. Grandey (2000) also concluded that both types of emotion regulation would lead to burnout, withdrawal, and negative work attitudes, but that researchers should examine this empirically. 
Grandey's (2000) propositions were examined by a recent meta-analysis that examined the last 30 years of research on emotional labor (Hülsheger \& Schewe, 2011). The meta-analysis revealed that this theoretical framework may not offer a complete understanding of emotion regulation in organizations. Hülsheger \& Schewe's (2011) findings confirmed that the theoretical models linking emotional labor to strain have overall been empirically supported, but only for emotion regulation through surface acting. Specifically, results indicated substantial relationships between both emotion-rule dissonance - an emotional state stemming from the incongruence between felt emotions and emotions that are required by display rules - and surface acting with indicators of strain ( $\rho$ s ranged from .39 to .48; Hülsheger \& Schewe, 2011). The relationship between deep acting and strain were much weaker ( $\rho$ s ranged from .05 to .18). Based on these results, the authors suggested that different mechanisms might be activated when employees engage in deep acting, compared to surface acting, and that this could explain the differential results. However, researchers would have to disentangle the processes involved in antecedent-focused emotion regulation in order to test this empirically. The authors acknowledged that global measures of deep acting found in the literature may not be well-suited to assess these different strategies, and suggested that future research should investigate other types of emotion regulation that could provide better suggestions and applications for employees and organizations.

There is some initial research indicating the utility of measuring specific emotion regulation strategies in the workplace. Diefendorff et al. (2008), using survey items derived from Gross' (1998) process model, found that employees used a range of 14 
different emotion regulation strategies, and these were linked to reports of work stressors and experienced discrete emotions. Some researchers have offered theoretical arguments in support of the suggestion by Hülsheger and Schewe (2011) that the conceptualization of emotion regulation using surface acting and deep acting may be a disadvantage to researchers on a theoretical level because these constructs may not measure the phenomenon of emotion regulation as completely as possible. For example, Holman, Martínez-Iñigo, and Totterdell (2009) reasoned that surface acting and deep acting might both be utilized to either amplify or suppress both positive and negative emotions. Furthermore, according to the findings of Diefendorff et al. (2008), the outcomes associated with this emotion regulation may depend on which type of specific emotion regulation strategy the individual uses to either amplify or suppress their emotions. Given that employees use different emotion regulation strategies, deep acting could be accomplished through different emotion regulation strategies and some of these may be conducive to strain, while others may be harmful for strain (Mikolajczak et al., 2009). By measuring these specific emotion regulation strategies, it may become clear under what circumstances deep acting is significantly associated with strain.

In addition, research that measures processes of emotion regulation in all workplace interactions - rather than limiting this assessment to customer-service interactions - may extend theories of emotion management in the workplace. As a result of its initial conceptualization (Hochschild, 1983), emotional labor studies have largely focused on service industry jobs or occupations that require 'people work,' which consist primarily of interactions with customers or clients and service employees. Emotion 
regulation, however, also takes place between coworkers and between supervisors and followers (Bono et al., 2007). Using an experience-sampling method (ESM) in a sample of 57 ambulatory health care workers, Bono et al. (2007) collected data 4 times per day for 2 weeks and used personal digital assistants (PDAs) to ask employees whether they were interacting with others (e.g., customers, coworkers, supervisors) and what their levels of strain and job satisfaction were. They found that employees who regulated their emotions experienced increased strain and decreased job satisfaction, and that the effects on strain tended to be longer-lasting than the effects on job satisfaction. By not limiting their measurement of emotion regulation to service encounters with customers, their findings suggest that emotion regulation occurs in a variety of interpersonal interactions, and these encounters can be related to strain. Therefore, in order to further research on emotion regulation in organizations, the present study will measure emotion regulation strategies used by employees across a variety of workplace interactions.

Next, I describe in greater detail the emotion regulation process proposed by Gross (1998), and the specific emotion regulation strategies that this study will focus on.

Emotion Regulation. Research on how individuals regulate their emotions has largely been guided by Gross' (1998) seminal work on emotion regulation. Gross (1998) defined emotion regulation as "the processes by which individuals influence which emotions they have, when they have them, and how they experience and express these emotions" (p. 275). All of the conscious and non-conscious strategies individuals use to increase, maintain, or decrease one or more components (i.e., feelings, behaviors, 
physiological responses) of an emotional response are forms of emotional regulation under Gross’ (1998) model.

Gross (1998) proposed a process model to explain how emotions are generated and at which points an individual may regulate these emotions. According to the model, specific strategies for regulating emotions can be differentiated along a timeline of the emotional response as it unfolds. At the broadest level, Gross (1998) distinguished between antecedent-focused and response-focused emotion regulation strategies. Antecedent-focused strategies refer to the things individuals can do before the emotion response tendencies have become fully activated and have changed the individual's behavior and peripheral physiological responding. Response-focused strategies refer to the things individuals can do once an emotion is already underway, after the response tendencies have already been generated. These strategies are therefore classified by when they have a primary impact on the process of generating emotions. Neurological evidence supports Gross' (1998) process model of emotion regulation: Empirical findings have bolstered the proposition that the effects of these strategies have different temporal trajectories that impact emotion experience, behavior, and neural systems (Goldin, McRae, Ramel, \& Gross, 2008). Finally, though these processes may be executed through conscious means, researchers tend to believe they often occur automatically and unconsciously (Gross \& John, 2003).

Researchers have suggested focusing on specific antecedent-focused and response-focused emotional regulation strategies (Gross \& John, 2003). In this way, the potential applications of the findings can be more accessible and less convoluted for 
employees and organizations. Additionally, by including one strategy that is antecedentfocused and one that is response-focused, the findings of this study can be readily compared to existing research on emotional labor. The two strategies used in this study are strategies that people commonly use in everyday life (Gross, 1998), including during the hours they are at work. Using Gross' (1998) model as a framework, the type of antecedent-based strategy this study will examine is cognitive reappraisal. Cognitive reappraisal (henceforth, reappraisal) is a form of cognitive change that involves construing a potentially emotion-eliciting situation in a way that changes its emotional impact (Lazarus \& Alfert, 1964). For example, a corrections officer might view an interaction with a supervising officer as an opportunity to obtain useful job-related advice from a veteran of the occupation, rather than a chance for the supervisor to criticize the officer's performance. Secondly, the type of response-focused emotion regulation strategy this study will examine is expressive suppression (henceforth, suppression), a form of response modulation that involves inhibiting ongoing emotion-expressive behavior (Gross, 1998). For example, a corrections officer may smile and nod in agreement when listening to a co-worker complain about a new staff policy - even though the officer likes the new policy - in order to avoid workplace confrontations. Gross (2001) theorized that because reappraisal occurs early in the emotiongenerative process and neutralizes a potentially emotion-eliciting situation at a cognitive level that reappraisal should decrease experiential, behavioral, and physiological responses within an individual. Suppression operates differently: By occurring later in the emotion-generative process, suppression requires active inhibition of emotion-expressive 
behavior that is generated during the unfolding of the emotion. As such, suppression should not change the experience of the emotion, but should increase physiological activation due to the effort required to actively inhibit ongoing emotion-expressive behaviors. Empirical work has largely supported these postulations in experimental settings (e.g., Gross \& John, 2003). This study aims to build on these findings to determine whether there is evidence that their results could be generalized to the workplace. As the authors pointed out while summarizing the results of a series of studies, they employed a relatively homogenous sample of college-aged research participants in all of their studies (Gross \& John, 2003). Therefore, it could not be determined with certainty whether these results would hold across a population of individuals with greater variation in age.

Ego-depletion model. By regulating emotions while at work, employees may be engaging in an effortful process that consumes the individual's resources. As such, how an individual regulates their emotions may have consequences for an individual after repeated acts of self-control. The strength model of self-control stipulates that the self's acts of volition (i.e., making choices and decisions, taking responsibility, initiating and inhibiting behavior, and making plans of action and carrying out those plans) draw on some limited resource and that these acts of volition will have a detrimental effect on future acts of volition and will impair cognitive function, resulting in a state of $e g o-$ depletion (Baumeister, Bratslavsky, Muraven, Tice, 1998; Grandey, 2000; Hagger, Wood, Stiff, \& Chatzisarantis, 2010). Research has suggested that suppression is one type of self-regulation that draws on this limited resource and, that these acts of volition have 
a detrimental effect on future performance (Baumeister et al., 1998; Richards \& Gross, 1999). Baumeister et al. (1998) showed that participants in one study who were told to refrain from showing or feeling any emotions during a movie performed worse at a subsequent task of solving anagram puzzles than participants who were told to express their emotions without attempting to hide or deny any feelings. These findings suggest that some valuable resource of the self was depleted in the participants who attempted to suppress or deny their emotions, and the same resource was depleted in participants attempting seemingly different and unrelated tasks. Research has also suggested that engaging in self-regulation requires energy and attention - indicated by increased cardiovascular activation (Richards \& Gross, 1999) - which can lead to exhaustion (Goldberg \& Grandey, 2007). Findings suggest that employees who suppress their emotions will deplete attentional and cognitive resources and experience strain, and metaanalytic findings have supported this model of ego-depletion (Hagger et al., 2010)

The ego-depletion model, however, has limitations in explaining the differential findings involving emotion regulation. The ego-depletion model suggests that emotion regulation using reappraisal should also consume some limited resource and impair cognitive function. Even though reappraisal has been theorized to consume fewer resources than suppression (Gross, 1998) - by occurring earlier in the emotion-generative process - the ego-depletion model would still predict a positive or null relationship between reappraisal and strain, as it is would be depleting some common resource (i.e., energy) within an individual. However, research has found negative associations between reappraisal and strain in experimental settings (e.g., Gross \& John, 2003), as well as 
between deep acting and strain in some field settings (e.g., Brotheridge \& Grandey, 2002; Kruml \& Geddes, 2000).

Therefore, the ego-depletion model cannot be used to explain exactly why reappraisal should be negatively associated will strain. A different theoretical perspective may be necessary to fully comprehend how different emotion regulation strategies can have different associations with effort expenditure and strain. Below, I explain how conservation of resources theory (Hobfoll, 1989) can be utilized to achieve a more complete understanding of this phenomenon.

Conservation of resources theory. Conservation of resources (COR) theory (Hobfoll, 1989) uses a resource perspective to explain how strain reactions develop within an individual. The first and central assumption of the theory is that people attempt to obtain, retain, and protect resources, and that strain occurs when an individual loses resources, or risks losing resources (Hobfoll, 2002). Resources can be objects (e.g., a home), conditions (e.g., marriage), personal characteristics (e.g., self-efficacy), or energies (e.g., time, money, knowledge). These resources are characterized as being valued by the individual or serving as means for the attainment of other resources. Further, the first assumption proposes that when faced with a stressor an individual will expend resources to address its presence. Strain develops, then, if dealing with the stressor is unsuccessful or if many resources are expended. For example, if at the end of a shift, a corrections officer is told their replacement has not shown up for work and they must work the next 8-hour shift, the officer may experience strain reactions in the second shift as they may have less energy and less ability to concentrate after already having 
worked the previous shift. Upon subsequent resource expenditure, a loss spiral may develop in which stress develops and resources are continually depleted. Using the same example, this corrections officer may already be tired and exhausted from working their previous double shift before their next regular shift starts. Getting through their normal workday may be more taxing due to their weary state, and subsequently when they arrive at home they would be more exhausted than the day before.

The second assumption of COR theory is that resources can generate new or additional resources (Hobfoll, 2002). Hobfoll proposed that in the absence of stressors an individual strives to obtain more resources. As a result, an individual can store resources that can be expended in more trying times. Additionally, strain is thought to decrease because the individual values the presence of additional resources. Another way one might gain resources is through utilizing the resources one already possesses to gain more resources. Through these two processes - obtaining new resources and generating more resources through possession of these resources - resources appear to accumulate through a gain spiral. This gain spiral is related to the next three assumptions of COR theory. Third, individuals who possess more resources have a higher likelihood of avoiding situations in which resources may be expended, allowing for a further gain of resources. Fourth, if individuals who possess more resources encounter situations that demand resource expenditure, they will be better prepared to address the situation. Fifth, as these individuals possess more resources, they will be less negatively affected when they expend resources to deal with a stressor, as they possess substitute resources to draw from. Furthermore, the sixth assumption of COR theory stipulates that the influence of 
resources tends to hold across time and circumstances. In this sense, the value resources hold for individuals is not fleeting or temporary. Lastly, the seventh assumption proposes that as resources are valued in their own right, individuals who possess more resources are viewed in a favorable light by both themselves and others.

COR theory can also be applied to answering the question of why the emotion regulation strategies of suppression and reappraisal may have differential effects for individual outcomes. Individuals who regulate their emotions through reappraisal may be contributing to the gain spiral described by COR theory. As discussed, reappraisal can occur early enough in the emotion generation process to potentially alter the entire subsequent trajectory of an emotion (Gross \& John, 2003). In doing so, reappraisal uses fewer resources than suppression in the regulation of one's emotions, as reappraisal does not require the repeated and effortful act of self-regulation that is characteristic of suppression (Gross, 2001). When a situation no longer requires emotion regulation, the individual is left with an excess of resources. Based on the assumptions of COR theory, the individual may use this opportunity to seek new resources, and use the resources they have retained to generate new resources, thus creating a gain spiral (Hobfoll, 1989). COR theory further suggests that individuals who have used reappraisal - and thus have retained more resources - will be more likely to avoid resource-consuming situations, will be more prepared to address these situations when they do face them, and will be less negatively affected by the expenditure of resources due to their greater amount of resources. All of these factors may contribute to reduced strain for the employee. 
COR theory may also be applied to explain that regulating emotions through suppression contributes to a loss spiral of resources (Hobfoll, 1989). This argument is elucidated by one consequence of the assumptions of COR theory: Dealing with stressors can induce further resource loss if the primary stressor (i.e., a situation that requires emotion regulation) evokes a response that is ineffective (i.e., suppression; Hobfoll, 2002). In this case, any gains achieved through dealing with the stressor are outweighed by the loss of the effortful expenditure associated with suppression. Studies have shown that suppression requires attentional and energy resources such as increased cardiovascular activation and impaired memory (e.g., Richards \& Gross, 1999). Furthermore, suppression, compared with showing or more directly addressing one's feelings, can result in fewer social resources through having a reduced social connection with others (Butler et al., 2003; Côté, 2005). As suppression consumes resources and leaves an individual with little or no supplemental resources, COR theory suggests their strain may increase based on the fact that they have fewer resources that can be valued, and have fewer resources to seek out additional resources, both of which would contribute to strain.

Grandey, Foo, Groth, and Goodwin (2012) incorporated COR theory in a study that examined how emotion regulation contributed to burnout. The authors surveyed 359 health care providers nested within 48 units in a large metropolitan hospital and asked about how much patient-initiated mistreatment they experienced, how often they engaged in surface acting, their strain, and how a unit-level construct, climate of authenticity, moderated the effect of surface acting on strain. Based on the assumptions of COR 
theory, Grandey et al. (2012) reasoned that increased strain would partially be explained by the resource losses resulting from the use of surface acting during interactions with patients. As predicted, their findings indicated that surface acting partially mediated the effect of patient-initiated mistreatment on strain, indicating that patient-initiated mistreatment had an indirect effect on strain through the influence of surface acting. They additionally reasoned that climate of authenticity, measured at the unit-level, could serve as an opportunity to replenish resources lost during surface acting. Their findings corroborated this hypothesis, as climate of authenticity significantly moderated the relationship between surface acting and strain.

\section{Employee Strain}

In the current study, two constructs will be used to conceptualize employee strain: burnout and psychological distress.

Burnout. Burnout is an affective reaction to ongoing stressors characterized by high levels of exhaustion and negative attitudes towards one's work (Maslach et al., 2001). More specifically, Demerouti, Bakker, Nachreiner, and Schaufeli (2001) conceptualize burnout as consisting of two dimensions: exhaustion and disengagement. Exhaustion is defined as a consequence of intensive physical, affective, and cognitive strain, perhaps as a long-term consequence of prolonged exposure to work demands. Disengagement refers to distancing oneself from one's work, and experiencing negative attitudes toward the work object, work content, or one's work in general. Since research has suggested that features of the job environment (e.g., chronic workload) are strongly 
related to burnout, burnout is an especially relevant outcome in the work context (Lee \& Ashforth, 1996).

Most research suggests that job characteristics, such as chronic stress from high workload, are the strongest predictors of burnout (e.g., Melamed et al., 2006). Many studies have examined burnout and have identified a number of correlates of burnout. A meta-analysis by Lee and Ashforth (1996) found that across 61 studies job stressors role conflict, role stress, stressful events, workload, and work pressure - were strongly, positively correlated with exhaustion. Several support resources were negatively correlated with exhaustion (i.e., having a community bond and family resources); several job enhancement opportunities were negatively correlated with exhaustion (i.e., innovation, participation, skill utilization, task orientation); reinforcement contingencies were correlated with exhaustion (i.e., unmet expectations and noncontingent punishments were positively related, contingent rewards were negatively related). Additionally, control coping and organizational commitment were negatively related, and turnover intentions were positively related, to exhaustion. Depersonalization (conceptually similar to disengagement; Demerouti et al., 2001) was strongly correlated with some similar, but some different, work characteristics. The consequences of burnout appear to be numerous. Research has identified various outcomes of burnout for employees, including increased risk of cardiovascular disease and sleep disturbances (Melamed et al., 2006). Burnout may also predict reduced commitment, decreased job satisfaction, increased turnover intentions (Shirom, 2003). 
Psychological distress. Regulating one's emotions at work additionally also has the potential to affect the mental and psychological strain of employees. As such, this study will examine an outcome measure of general psychological distress, or a general indicator of the presence of a mental disorder (Kessler et al., 2002). ${ }^{1}$ Individuals suffering from a wide variety of mental disorders tend to share cognitive, behavioral, emotional, and psychophysiological symptoms (Dohrenwend, Shrout, Ergi, \& Mendelsohn, 1980), and the presence of these may manifest itself as psychological distress. Kessler et al. (2002) have suggested that measures of general psychological distress are useful as tools for screening for mental illness.

Psychological distress can refer to clinical mental health illnesses, but it has also been conceptualized as similar to strain, depression, or anxiety when studied in the workplace. Across occupations, high amounts of job demands have been positively associated with greater psychological distress (Marshall, Barnett, \& Sayer, 1997). Though psychological distress is not as often studied as an outcome variable as a less severe type of strain outcome, it may be more particularly relevant in certain occupations, such as corrections, as recent research has suggested. In a study of 220 corrections officers, Obidoa et al. (2011) found that $31 \%$ of the participant scores for psychological distress indicated the presence of serious psychological distress, or depression.

\footnotetext{
1 Though mental health is often assessed through fully structured research diagnostic interviews, Kessler et al. (2002) developed a short scale to screen for the presence of non-specific psychological distress. The scale development was motivated by a review of mental health screening scales developed prior to 1980 . The scale that Kessler et al. (2002) developed aimed to measure the presence of general psychological distress among individuals. In this way, measuring psychological distress using Kessler et al.'s (2002) can be an efficient tool for identifying the presence of the symptoms characteristic of a variety of serious mental illnesses without conducting a full clinical diagnostic interview.
} 


\section{Emotion Regulation and Employee Strain}

I offer three explanations for how reappraisal and suppression will be linked to employee strain. First, according to the process in which emotions are generated and emotion regulation occurs, suppression occurs late in the emotion generative process and requires the individual to continually exert effort to manage the emotion response tendencies as they arise (Gross \& John, 2003). Repeated efforts to suppress emotions may consume cognitive resources that may otherwise be used in the social contexts in

which these emotions arise (e.g., Richards \& Gross, 1999). Second, suppression creates a sense of incongruence within an individual, or a discrepancy between their inner experience and outward expression of emotions (John \& Gross, 2004). This sense of inauthenticity may be associated with negative feelings about the individual and alienate the individual from others and even themselves (Sheldon, Ryan, Rawsthorne, \& Ilardi, 1997), possibly contributing to strain. Third, I argue that the gain spiral process postulated by COR theory offers an explanation in which individuals can continually gain resources that will likely be associated with reappraisal (Hobfoll, 1989). Oppositely, individuals can continually lose resources through a loss spiral, and I propose this will be associated with suppression.

Past research suggests there could be a negative relationship between certain types of antecedent-focused strategies and strain, despite recent meta-analytic findings (Hülsheger and Schewe, 2011) that suggested a null relationship. For instance, Kruml and Geddes (2000) found that among a sample of 427 service employees, surface acting was positively associated with burnout, as expected, but deep acting was negatively 
associated with burnout. The authors noted that employees who expressed their true feelings (i.e., were deep acting) were in better health than those who faked their emotions (i.e., were surface acting). Thus, these suggest that deep acting may not be weakly associated with strain in a positive direction, but that the relationship may be negative under certain circumstances. In Kruml and Geddes' (2000) study, for instance, the workers may have used different strategies to engage in deep acting than workers in other studies did (e.g., reappraisal), accounting for the negative relationship between deep acting and strain.

To specifically examine whether emotion regulation processes were associated with different outcomes, Gross and John (2003) conducted a series of studies to examine the differential outcomes associated with reappraisal and suppression emotion regulation strategies. Specifically, they found that when individuals tended to use reappraisal to regulate emotions, these individuals experienced less general strain (e.g., positive relations with others, personal growth, life satisfaction; $\beta$ s ranged from .23 to .41 ), and lower levels of depression ( $\beta \mathrm{s}$ ranged from -.23 to -.29). Conversely, individuals who used suppression to regulate emotions experienced more strain, ( $\beta$ s ranged from - .22 to .46), and higher levels of depression ( $\beta$ s ranged from .23 to .27). Gross and John (2003) also found that individuals who tended to reappraise emotions experienced more positive emotions ( $\beta \mathrm{s}=.42$ for mood, .35 for discrete emotions) and fewer negative emotions ( $\beta \mathrm{s}$ $=-51$ for mood, -.47 for discrete emotions), while individuals who tended to use suppression experienced fewer positive emotions ( $\beta \mathrm{s}=-.33$ for mood, -.58 for discrete emotions) and more negative emotions ( $\beta \mathrm{s}=.39$ for mood, .36 for discrete emotions). 
Overall, the authors concluded their results indicated that there is strong evidence for a set of divergent outcomes associated with reappraisal and suppression across several independent samples.

Therefore, I hypothesize that when emotion regulation strategies are measured in the workplace, reappraisal of emotions will be negatively related to strain (i.e., burnout and psychological distress), and that suppression of emotions will be positively related to strain.

Hypothesis 1a: Engaging in reappraisal to regulate emotions at work will be negatively related to strain.

Hypothesis 1b: Engaging in suppression to regulate emotions at work will be positively related to strain.

\section{Emotion Regulation and Recovery Experiences}

This study will also examine relationships between emotion regulation strategies and recovery experiences outside of work. Recovery from work can be described as the process during which individual functions that have been called upon during work return to their prestressor levels (Meijman \& Mulder, 1998). The recovery process has been conceptualized as a psycho-physiological process opposite of the strain process, in which an individual's psychobiological systems that have been stressed return to their prestressor levels. Research on recovery from work suggests that employees can recover from work (e.g., after their shift ends, during evenings, on weekends) by removing themselves from work demands and engaging in nonwork-related activities (Sonnentag \& Fritz, 2007). Research on recovery from work has revealed that this recovery time is 
necessary for individuals to allow the psychobiological systems that were activated during work to re-stabilize and to replenish resources (e.g., affective states, well-being) that were lost during the workday (e.g. Fritz, Sonnentag, Spector, \& Monroe, 2010; Siltaloppi, Kinnunen, \& Feldt, 2009; Sonnentag \& Fritz, 2007). Individuals who are unable to fully recover from work demands are likely to experience detrimental health outcomes, including depressive symptoms, burnout, increased health complaints, and increased risk of mortality (Kivimäki et al., 2006; Sonnentag \& Fritz, 2007).

Sonnentag and Fritz (2007) identified underlying experiences that are common among many specific recovery activities. For this study, I propose that emotion regulation will be associated with three of these experiences: Psychological detachment, relaxation, and mastery. Psychological detachment is described as an "individual's sense of being away from the work situation" (Etzion, Eden, \& Lapidot, 1998, p. 579); individuals who are psychologically detached from work are both separated from the physical work situation and refrain from thinking about work or job-related problems or opportunities (Sonnentag \& Fritz, 2007). Relaxation is characterized by a state of low activation and increased positive affect (Stone, Kennedy-Moore, \& Neale, 1995), and is associated with activities such as meditation or taking a light walk. Mastery experiences are off-job activities that distract from the job by providing challenging experiences and learning opportunities in other domains, such as learning a new language or building something as part of a hobby (Fritz \& Sonnentag, 2006).

The ways in which recovery experiences affect strain have been explained in previous studies by several theoretical frameworks. In the following sections, I briefly 
discuss the two most prominent theories in the recovery literature: The effort-recovery model and COR theory. I then give an overview of research findings regarding predictors of recovery experiences, and discuss how the two types of emotion regulation strategies (i.e., reappraisal and suppression) can either hinder or contribute to the processes that explain recovery.

Effort-recovery model. The effort-recovery model (E-R model; Meijman \& Mulder, 1998) provides a conceptual framework to explain the process of recovery from work. Recovery refers to a process in which an individual's functional systems that have been called upon during work return to their prestressor levels. The E-R model explains that expending effort at work leads to load reactions, which can include physiological, behavioral, and subjective responses to effort expenditure. Load reactions can occur as a result of performing activities at work - in other words, they are a byproduct of the effort one exerts in the course of completing tasks at work (e.g., the eye strain one experiences from staring at a computer; Meijman \& Mulder, 1998). Recovery, therefore, occurs when the individual is no longer faced with work demands or demands similar to those they experience at work, and built-up load reactions are diminished. Adequate recovery can result in restored mood and decreased physiological strain (Sonnentag \& Fritz, 2007). This recovery process, therefore, can be perceived as the opposite of the strain process. If the psycho-physiological systems that are taxed during work are not allowed to recover, the E-R model explains that this incomplete recovery process will require the individual to expend more resources to offset the unfinished recovery in order to perform at work. 
As load reactions continue to accumulate without proper recovery, individual strain may increase.

Conservation of resources theory. As discussed previously, COR theory (Hobfoll, 1989) proposes that strain reactions may develop within an individual when resources are threatened or when an individual actually experiences a loss of resources. In the context of recovery from work, COR theory can be used to explain how an individual can reverse this process and rebuild their resources. Recovery researchers have used COR theory to explain that individuals who engage in recovery experiences outside of work can restore or replenish resources, especially internal resources such as energy, selfefficacy, and positive mood, that have been expended or lost while working (Fritz et al., 2010; Sonnentag \& Fritz, 2007). Recovery experiences that either build new resources or replenish ones that have been threatened or lost can assist an individual in overcoming strain reactions resulting from resources lost while working (Moreno-Jiménez et al., 2009; Sonnentag, Binnewies, \& Mojza, 2008). Findings from studies on recovery experiences have been fairly consistent with one of the assumptions of COR theory: In the absence of stressors, individuals strive to obtain resources (Hobfoll, 1989, 2002).

Predictors of recovery. While early studies on recovery from work focused mainly on the effects that time away from work had on strain and job performance, more recent research has started identifying workplace and individual factors that either aid or hinder recovery experiences during nonwork time. These findings indicate that specific job demands and job stressors can interfere with the recovery experiences one has outside of work. One study found that workload during the day, specifically chronic time 
pressure and day-specific work hours, led to a lower likelihood that individuals were able to psychologically detach from work during evenings (Sonnentag \& Bayer, 2005). Other studies have provided additional evidence that situational job characteristics such as time pressure, role ambiguity, situational constraints, and hours of overtime are negatively associated with psychological detachment (Sonnentag \& Fritz, 2007), perhaps through the increase in rumination, prolonged activation, and negative affect associated with increased demands (Cropley \& Purvis, 2003).

So far, few studies have examined predictors of recovery experiences that are conceptually similar to emotion regulation. Volmer, Binnewies, Sonnentag, and Niessen (2012) focused their study on social conflicts with customers among a sample of civil service agents, and whether these negative interactions had an effect on nonwork recovery experiences. The authors argued that these conflicts are typically brief, negative interactions that offer the employee no opportunity to address or resolve any consequences from these interactions after they occur. As expected, they found that daily social conflicts with customers were negatively associated with psychological detachment, and positively associated with negative work reflection, or considering the negative aspects of one's job (Fritz \& Sonnentag, 2006), among civil service agents during nonwork time.

One study examined a similar construct that was conceptualized as a workplace stressor - emotional dissonance - and found that emotional dissonance was associated with lower levels of psychological detachment in a sample of Protestant pastors (Sonnentag et al., 2010). Another recent study also found that emotional dissonance 
during the workday predicted lower levels of positive work reflection, or thinking about the positive aspects of one's work, after working hours (Sonnentag \& Grant, 2012). Both of these studies were among the first to explore the relationship between emotional dissonance and recovery from work. In the present study, I aim to extend the research on recovery and emotion regulation in several ways. First, while the previous studies only found relationships among experiences related to mental disengagement and emotional dissonance, I propose that three recovery experiences will be linked with emotion regulation strategies. Second, I also reason that examining the link between specific emotion regulation strategies and recovery experiences may yield specific, interpretable results with potential applications, and that these relationships exist in an occupation (i.e., corrections) previously unexamined in recovery research.

\section{Emotion Regulation and Recovery Experiences}

In the current study, I postulate that depending on the type of emotion regulation strategies an employee uses at work, their nonwork recovery experiences may either be enhanced or hindered. Specifically, I argue that reappraisal will be positively related to recovery experiences. Experimental findings support the idea that implementing reappraisal strategies may influence neural, experiential, and behavioral manifestations of emotion over time (Goldin et al., 2008). When employees who tend to reappraise emotions in work situations leave work, they have likely reduced the consequences of negative interactions and experiences that they experienced, leaving them with fewer situations to ruminate on. This would be associated with a reduction of perseverative 
thinking and increased cognitive resources, allowing the individual to engage in psychological detachment.

Employees who use reappraisal should experience higher levels of relaxation as well. Empirical evidence shows individuals who tend to use reappraisal also experience positive emotions (Gross \& John, 2003), which may be related to their ability to relax. Relaxation is characterized by the presence of low-activated positive affect (Stone et al., 1995), and the positive emotions that the employee who reappraises carries over from the workplace could help to facilitate relaxation experiences. This transfer of personal resources (i.e., positive emotions) could contribute to improved experiences at home that are relaxing.

Individuals who reappraise and experience more positive emotions may also be more likely to engage in mastery experiences. Mastery experiences require an investment of self-regulatory resources (Sonnentag \& Fritz, 2007). As previously noted, reappraisal occurs earlier in the emotion generative process, thus requiring fewer resources to use and preserving more resources for the individual (Gross, 1998). Employees who reappraise emotions at work will be able to transfer more resources from the workplace to their nonwork domain, of which they can invest in mastery experiences. In summary, I hypothesize that reappraisal will be positively related to recovery experiences.

Hypothesis $2 a$ : Reappraisal will be positively related to recovery experiences (psychological detachment, relaxation, and mastery) during nonwork time. Oppositely, I argue that suppression is likely to interfere with recovery experiences. Experimental findings suggest that the sustained activation resulting from 
suppression may be physiologically taxing and may disturb physiological and psychological functioning (Goldin et al., 2008). As suppression theoretically is unhelpful in reducing the experience of negative emotion (Gross, 1998), these emotions arising from negative work experiences may remain unresolved and linger past the end of the workday. An employee that employs suppression during an unpleasant interaction with a coworker, for instance, may ruminate or continue to think about this interaction while they are away from work. This is consistent with findings that have shown suppression to be associated with rumination (Gross \& John, 2003).

Similarly, the employee who continues to ruminate over unresolved emotional encounters at work may experience increased cognitive and physiological activation. This increased activation may directly affect relaxation, as an individual may find it difficult to enjoy the low-activation state of relaxation while still highly activated from the day's events. There is also neurological evidence suggesting that although suppression can reduce negative emotion and behavior (i.e., facial expressions), it also sustains elevated responses in the amygdala and insula, suggesting the sustained activation characteristic of suppression can tax physical and psychological functioning (Goldin et al., 2008). This suggests that employees who repeatedly suppress emotions throughout the workday may accumulate load reactions that could interfere with their ability to relax (Meijman \& Mulder, 1998), as their physiological systems will remain in an active state.

Finally, suppression also consumes resources necessary for an individual to absorb themselves in certain recovery experiences. As a response-focused emotion regulation strategy, suppression requires the individual to engage in effortful 
management of their emotions, which is theorized to consume cognitive resources (Gross, 1998; Gross \& John, 2003). For these reasons, for individuals who tend to use suppression while at work, the consistent use of suppression may drain a greater amount of the employee's personal resources at the end of each day. This may leave the individual without the resources necessary to engage in the self-regulation needed to participate in mastery experiences (Sonnentag \& Fritz, 2007). In summary, I hypothesize that suppression will be negatively related to psychological detachment, relaxation, and mastery during nonwork time.

Hypothesis $2 b$ : Suppression will be negatively related to recovery experiences (psychological detachment, relaxation, and mastery) during nonwork time.

\section{Recovery Experiences and Employee Strain}

A large body of research has established that recovery experiences can lessen strain reactions stemming from the workplace (e.g., Moreno-Jiménez et al., 2009; Sonnentag \& Fritz, 2007; Volmer et al., 2012). Research on recovery experiences has shown that individuals who are unable to recover from work demands may suffer from impaired health and greater strain (e.g., Sonnentag \& Bayer, 2005; Sonnentag \& Fritz, 2007; Sonnentag et al., 2008). For example, Sonnentag et al. (2008) gathered daily survey data from 166 public administration employees over the course of one week. They found that a lack of psychological detachment in the evening was associated with higher fatigue the following morning. Relaxation in the evening was associated with serenity the next morning, and mastery experiences were associated with higher positive affect. This study illustrated that individuals can use daily recovery experiences to lessen their strain. Other 
studies have shown that individual can use other nonwork time to recuperate from work. For instance, Sonnentag et al. (2010) measured recovery experiences at the end of the weekend and affective experiences on the following Friday in a sample of German school teachers. They found that psychological detachment positively predicted feelings of serenity, and relaxation positively predicted feelings of joviality, self-assurance, and serenity, and negatively predicted fear and sadness. Mastery experiences were positively associated with joviality, self-assurance, and serenity experienced at the end of the weekend. Other studies have found that recovery was associated with lessened strain over vacation (Fritz \& Sonnentag, 2006), extended respite periods (i.e., sabbaticals; Davidson et al., 2010), and even during short breaks at work (Fritz, Lam, Spreitzer, 2011).

Studies on recovery have also specifically linked recovery experiences to burnout, psychological distress, and related outcomes. Sonnentag \& Fritz (2007) found that psychological detachment was linked to fewer health complaints, depressive symptoms, and sleep problems, lower emotional exhaustion and need for recovery, and higher levels of life satisfaction (Sonnentag \& Fritz, 2007). Relaxation was linked to fewer health complaints and sleep problems, lower levels of emotional exhaustion and need for recovery, and higher levels of life satisfaction. Mastery experiences were linked to fewer depressive symptoms, lower levels of emotional exhaustion and need for recovery, and higher levels of life satisfaction. Other studies that examined recovery experiences and strain have found similar results regarding burnout and psychological distress (i.e., Fritz \& Sonnentag, 2005; Marzuq \& Drach-Zahavy, 2012; Ragsdale, Beehr, Grebner, \& Han, 2011). Therefore, consistent with a number of past findings of the relationship between 
recovery experiences and strain, I hypothesize that employees' recovery experiences at work will negatively predict strain.

Hypothesis 3a: Psychological detachment will be negatively related to strain. Hypothesis $3 b$ : Relaxation will be negatively related to strain.

Hypothesis 3c: Mastery will be negatively related to strain.

\section{Recovery Experiences as a Mediator}

Recent research has begun to examine recovery (and incomplete recovery), as an underlying mechanism between job stressors and strain (Geurts \& Sonnentag, 2006; Kinnunen et al., 2011). Geurts and Sonnentag (2006) reviewed research on recovery and considered recovery to be a vital link between stressful work characteristics and employee health. Kinnunen et al. (2011) specifically argued that recovery experiences could be incorporated into the Job Demands-Resources model (JD-R; Demerouti et al., 2001). They reasoned that the JD-R could be expanded upon, as it does not take into account the role of personal resources in the relationship between work characteristics and strain. The explained that recovery experiences could be included in this model as a mediating mechanism, as recovery is a process that fosters and protects personal resources that can explain how job stressors can be associated with strain and health problems. Using the JD-R model and past research as a framework, the authors hypothesized that job demands would be factors that inhibited recovery, resulting in strain, while job resources could facilitate recovery, resulting in lessened strain (Demerouti, Bakker, Geurts, \& Taris, 2009). 
Kinnunen et al. (2011) named their addition to the JD-R model the Job-DemandsResources-Recovery (JD-R-R) model, and tested it using a sample of 527 Finnish employees from various occupations. The authors found partial support for their new model. First, they found that psychological detachment fully mediated the effects of job demands on fatigue at work. High demands at work were associated with poor psychological detachment from work, which in turn was associated with elevated levels of fatigue. Second, mastery partially mediated the effects of job resources on work engagement. The relationship between high job resources and high levels of work engagement were partially explained by high levels of mastery experiences. The results of this study suggest that an employee's experience job stressors affect their ability to engage in recovery experiences, which in turn can affect their health and strain.

Motivated by these recent findings, therefore, the current study aims to extend the past research by examining how recovery experiences act as a mediating mechanism between emotion regulation at work and strain. Employees who indicate habitual use of reappraisal at work may conserve more resources at work by using an emotion regulation strategy theorized to be less effortful (Gross, 1998). By conserving more resources and using a strategy that does not keep psychobiological systems activated for an extended period of time, these employees should be more easily able to engage in recovery experiences, which in turn will be negatively associated with strain. The opposite may be true for employees who indicate frequent use of suppression at work. Suppression is associated with negative physiological and psychological outcomes (Gross \& John, 2003). Employees who tend to regulate emotions through suppression are actively 
consuming resources. By using suppression, these employees are using more resources to regulate their emotions, effectively increasing the effects that job demands may have on their strain. Therefore, the result may be an association with a decreased ability to engage in recovery experiences, and higher levels of strain.

In sum, I argue that reappraisal as a structural, personal resource builds resources, like building a muscle, while suppression consistently consumes resources over time. Furthermore, I argue that recovery experiences are part of the mechanism that underlies the relationship between emotion regulation and strain. Specifically, employees who indicate high use of reappraisal will experience higher levels of recovery experiences during nonwork time, and higher levels of recovery experiences will be negatively associated with strain. Employees who indicate high use of suppression will experience lower levels of recovery experiences during nonwork time, and lower levels of recovery experiences will be negatively associated with well being. Finally, I propose this is a partial mediation, as recovery experiences may not be the sole mechanism linking emotion regulation to strain. For example, individuals who reappraise their emotions may foster a sense of congruence within oneself, which can directly and negatively affect strain, while individuals who suppress emotions contribute to strain through a sense of inner discrepancy (John \& Gross, 2004).

Hypothesis 4a: Recovery experiences will mediate the relationship between reappraisal and strain. Specifically, reappraisal will be positively related to recovery experiences, and higher levels of recovery experiences will be negatively related to strain. 
Hypothesis $4 b$ : Recovery experiences will mediate the relationship between suppression and strain. Specifically, suppression will be negatively related to recovery experiences and lower levels of recovery experiences will be positively related to strain.

\section{Does Coping Matter?}

In addition to the proposed mediation hypotheses, I take an exploratory approach to examine whether individual differences in the use of certain coping strategies may moderate the relationships between emotion regulation, recovery experiences, and strain. Including these differences in this study may provide more information about what types of factors contribute to individual strain in the current sample (Lazarus, 1999).

Research on coping has found that individuals tend to differ in their use of a variety of coping styles as a fairly stable individual difference (e.g., Carver et al., 1989;

Lazarus \& Folkman, 1984). These strategies individuals use to cope have been commonly researched using a distinction between two types of coping. Problem-focused coping is aimed at solving a problem or doing something to address the source of the stress. Emotion-focused coping is aimed at reducing or managing emotional distress associated with, or caused by, the situation (Carver et al., 1989; Lazarus \& Folkman, 1984). The current study will focus on emotion-focused coping in accordance with the "matching hypothesis" in work stress research (e.g., de Jonge \& Dormann, 2006). Research on the stressor-strain relationship has found that the type of factor that is theorized to buffer against strain should be especially successful when this factor corresponds to, or matches at an emotional or physical level, the type of stressor the individual is experiencing. As 
emotion regulation and strain are largely affective constructs, emotion-focused coping is theorized to be more closely 'matched' than problem-focused coping. Additionally, problem-focused coping has been theorized to be more relevant when an individual feels like something can be done about the situation, while emotion-focused coping may be more useful when the individual has little control over changing or mitigating the effect of the stressor (Carver et al., 1989). In the current study, it is possible that the corrections officers believe that regulating emotions is part of their job (Nylander et al., 2011), and therefore problem-focus coping has less potential utility. Accordingly, this study includes two coping strategies that an individual may be likely to use while under stress, namely, seeking social support for emotional reasons, and focus on and venting of emotions, which are defined in detail below.

\section{Emotion-focused Coping Strategies}

A specific coping strategy that could positively benefit an employee who engaged in emotion regulation is seeking social support for emotional reasons (henceforth, emotional social support), which includes getting moral support, sympathy, or understanding (Carver et al., 1989). This coping strategy may be a healthy way for individuals to release their feelings regarding their emotional strains. It may be functional in helping a person who feels insecure following a stressful situation to be reassured in a supportive manner. In this way, the support may also foster a return to problem-focused coping, which may ultimately be necessary to resolve the stressor. However, emotional social support is also considered by researchers to be a double-edged sword (Carver et al., 1989). If emotional social support is used by an individual to vent their feelings, it may 
not be functional in reducing the effect of the stressor. This may be related to the second type of coping strategy, focus on and venting of emotions (henceforth, venting emotions), a strategy which indicates a tendency to focus on the source of distress one is experiencing and to voice these feelings (Carver et al., 1989). This strategy may be associated with ruminating about these feelings for extended periods of time and could interfere with the ability to adjust to the situation. A recent review has indicated the effectiveness of these two strategies may be context-dependent (Stanton \& Low, 2012), and that these two strategies may be difficult to differentiate from one another.

Emotion-focused coping strategies may explain additional overall variance when included as a moderator of the relationships between emotion regulation, recovery experiences, and strain. By including it in these relationships, it is especially important to address how coping is related to, but conceptually different from, recovery experiences. Although the development of the recovery literature partially was influenced by the stress and coping tradition, recovery experiences are distinct from individual coping strategies in at least two ways. First, on a conceptual level, recovery experiences are the experiences an employee has when they are away from work (Sonnentag \& Fritz, 2007). Therefore, recovery experiences are domain-specific. Coping strategies, on the other hand, are individual differences that describe what the individual tends to do when they appraise a situation as stressful (Lazarus, 1999). An individual may employ these coping strategies while at work or while away from work. Second, some empirical evidence exists that differentiates coping and recovery experiences. Specifically, Sonnentag and Fritz (2007), using a large sample from various occupations, found that the recovery 
experiences included in the present study were correlated with coping [Psychological detachment ( $r=-.19$ for emotional social support, .07 for venting emotions), relaxation $(r$ $=.33, .16)$, and mastery $(r=.07, .03)]$. Overall, these findings indicate that recovery experiences were at best moderately related to coping strategies, providing some empirical support that they are separate constructs.

Possible mechanisms of emotion-focused coping. While emotion-focused coping has historically thought to be maladaptive, more recent research has suggested that individuals may protect themselves from strain in stressful situations by expressing their emotions (Stanton \& Low, 2012). To better understand under what circumstances an individual may benefit from emotion-focused coping, Stanton and Low (2012) suggested that the characteristics of the stressor, individual, social context, and emotion expressions themselves determine whether coping by expressing emotions is beneficial for reducing strain. The authors also suggested several mechanisms that may explain how emotional expression may be effective. First, labeling emotions is a process that may dampen their power: putting one's feelings into words can lessen the felt intensity of the emotion and reduce the activation in areas of the brain involved in emotion processing (i.e., the amygdala). Second, another explanation is that emotion expression can foster better understanding and appraisal of the situation, thus providing people with an opportunity to clarify their meaning of the situation. This is related to a third mechanism, namely that expressive coping can direct people towards important goals, identify impediments to goal achievement, and create pathways for accomplishing their goals. Furthermore, this type of coping can provide an opportunity to confront the source of stress, allowing for 
adjustment to the stressor over time and reduced physiological reactivity to thoughts or emotions about the stressor.

\section{Emotion-Focused Coping As a Moderator}

Within the literature on coping, some evidence supports the use of these specific emotion-focused coping strategies as moderators. Meta-analytic evidence suggests that general social support, or the availability and quality of relationships one has with others, plays an important role in the workplace (Viswesvaran, Sanchez, \& Fischer, 1999). General social support related to work stressors reduced strains experienced, mitigated perceived stressors, and moderated the stressor-strain relationship across 68 studies (Viswesvaran et al., 1999). Other studies have found that the proposed coping strategies are linked with strain. For example, Litman \& Lunsford (2009) found that the frequency of using emotional social support was negatively related to diminishment, or feelings of helplessness, reduced self-esteem, and greater pessimism, while venting emotions positively predicted diminishment after a stressful event.

It is possible that coping strategies moderate three of the previously proposed relationships. First, coping that occurs after leaving work and before an employee engages in a recovery experience could reduce the spillover of strain into the employee's nonwork domain. Successful coping could help reduce the occurrence of ruminating thoughts and allow the individual to detach, relax, or engage in mastery experiences without feeling distracted. Second, coping could moderate the relationship between emotion regulation and strain. Here, successful or beneficial coping could directly buffer the impact on strain for individuals who tend to suppress their emotions at work by 
providing an outlet for addressing the suppressed feelings. Or, coping could further enhance the negative association between reappraisal and strain by providing an additional structural resource that the employee will value, regardless of the frequency in which they actually engage in coping. Lastly, coping could be useful after a recovery experience and further lessen strain. Even though the link between recovery and strain has been previously established, it may be helpful to first engage in a recovery experience to take a break from the stressors at work, then address the specific stressor through coping.

Research Question 1: Will coping strategies (emotional social support, venting emotions) moderate the relationship between emotion regulation and recovery experiences?

Research Question 2: Will coping strategies moderate the relationship between emotion regulation and strain?

Research Question 3: Will coping strategies moderate the relationship between recovery experiences and strain? 


\section{Chapter 2}

Method

\section{Participants and Procedure}

Participants in this study were corrections officers employed by the state of

Oregon. The data were collected as part of an ongoing research project. Surveys were distributed among all 14 correctional institutions in the state over a period of several months by staggering the distribution of the survey to groups of institutions. For each institution, an email invitation was sent to all correctional officers by 1) the superintendent of the institution, 2) a union representative, and 3) a member of the research department. The emails contained directions for taking the survey, and included both a link to the online version and directions for how to acquire a paper version of the study, if preferred. Participants were informed that a survey was being conducted to examine work stress and strain among correctional officers. Participants were told that the survey would be available for them to take for two weeks. After one week, the superintendent sent a reminder email out to their institution and emphasized how valuable each individual response was. The documents described here can be found in Appendices B-H. More information about each facility is presented in Appendix I.

There are 2,461 corrections officers employed by the state. A total of 1,370 corrections officers took the survey for an initial response rate of 54\%. Thirty-nine of the respondents indicated that they did not work as a security staff member, and were excluded from analysis. Additionally, we received 14 responses from a team of officers who transport offenders between facilities and judicial facilities, and we excluded these 
responses from analysis as well, leaving a total sample size of $\mathrm{N}=1317$. Upon further examination of the data, we discovered that some of the surveys were not completed. To address this, we used listwise deletion in analyses where appropriate. Therefore, the sample size for each analysis varied, depending on how many participants responded to the variables included in the analysis.

In the survey, we informed the participants that their responses would be anonymous. The online survey and the paper survey contained the same questions. The paper survey packets included one survey and a stamped envelope addressed to the researchers. The online survey was operated through the online survey software Qualtrics, and responses were sent directly to the researchers.

Prior to developing and distributing the survey, our research team ${ }^{2}$ conducted site visits at three of the facilities in the study. The purpose of these site visits was to make observations of the work environment of the corrections officers to inform our choices of what items should be included on the survey. The particular sites were chosen in order to make observations at minimum (Columbia River Correctional Institution), medium (Coffee Creek Correctional Facility), and maximum (Oregon State Penitentiary) security facilities. During each visit, we met with members of the representing union and administration and were given a tour of the facility. During the tour, we recorded our observations and asked questions. After touring the facility, we conducted interviews with two corrections officers at each facility. These officers were selected with the help of the administration and union representatives so we were able to speak with officers

\footnotetext{
2 The author was a member of the research team, along with Dr. Charlotte Fritz, Dr. Leslie Hammer, and David Meier.
} 
with varying years of service from different backgrounds. The interviews were semistructured; we brought a list of pre-determined questions to each interview, but allowed the topics to vary based on the responses of each officer. After all of our site visits had concluded, we developed a survey that we believed would best quantify a wide variety of workplace factors that had either been identified by past research or that we had observed during our site visits.

\section{Measures}

Select measures from the survey were used in the present study. The measures of emotion regulation, recovery experiences, and strain asked the participant to refer to the past month as a time frame for their responses. The measures of coping strategies asked the participant to answer regarding how they generally respond to stressors.

Emotion regulation. The Emotion Regulation Questionnaire (ERQ; Gross \& John, 2003) was used to measure suppression and reappraisal as emotion regulation strategies. The ERQ consisted of ten items on a 5-point rating scale, ranging from 1 (Not at all) to 5 (Very much). The scale was modified by adding the phrase 'while at work' to the directions for the scale. Research has shown that the validity of personality-type scales can be improved by changing the frame of reference to focus on the workplace (Hunthausen, Truxillo, Bauer, \& Hammer, 2003; Shaffer \& Postlethwaite, 2012). The reappraisal subscale consisted of six items. A sample item from this scale was "I control my emotions by changing the way I think about the situation I'm in." Cronbach's alpha for reappraisal in this sample was .88. The suppression subscale consisted of four items. 
A sample item from the scale was "I keep my emotions to myself." Cronbach's alpha for the scale was .76 .

Strain. The Oldenburg Burnout Inventory (OLBI; Demerouti, Bakker, Vardakou, \& Kantas, 2003) was used to assess exhaustion and disengagement as two dimensions of burnout. The OLBI consisted of sixteen items on a 5-point rating scale, ranging from 1 (Not at all) to 5 (Very much). The exhaustion subscale consisted of eight items. A sample item from the scale was "After my work, I needed more time to relax than in the past to become fit again." Cronbach's alpha for the scale was .85 . The disengagement subscale consisted of eight items. A sample item from the scale was "I tended to think less during my work and just execute it mechanically." Cronbach's alpha for the scale was .76. For each of the scales, four items were reverse-coded.

The K-6 was used to assess psychological distress (Kessler et al., 2002). The scale consisted of six items on a 5-point rating system, ranging from 1 (none of the time) to 5 (all of the time). The scale asked the participants how often in the past month they felt one of the response options, with a sample being "so sad that nothing could cheer you up?" Cronbach's alpha for the scale was .88 .

Recovery experiences. The Recovery Experience Questionnaire (REQ; Sonnentag \& Fritz, 2007) was used to measure psychological detachment, relaxation, and mastery experiences during nonwork time. Each subscale of the REQ consisted of four items on a 5-point rating scale, ranging from 1 (Not at all) to 5 (Very much). A sample item from the psychological detachment scale was "I forgot about my work." Cronbach's alpha for the scale was .74. A sample item from the relaxation scale was "I kicked back 
and relaxed." Cronbach's alpha for the scale was .91. A sample item from the mastery scale was "I learned new things." Cronbach's alpha for the scale was .86.

Coping. Two subscales from the COPE were used to measure how often a participant typically employs a certain coping strategy when they encounter stress (Carver et al., 1989). Each subscale consisted of four items on a 5-point rating system, ranging from 1 (never) to 5 (always). A sample item from the seeking social support for emotional reasons subscale was "I try to get emotional support from friends or relatives." Cronbach's alpha for the scale was .89. A sample item from the focus on and venting of emotions subscale was "I get upset and let my emotions out." Cronbach's alpha for the scale was .72 .

Control Variables. Several control variables were included in the study. First, gender was controlled for in the analyses, as research on emotion regulation has indicated that men tend to suppress their emotions more frequently than women (Gross \& John, 2003). Second, age was controlled for, as some research has suggested that individuals reappraise emotions with greater frequency as they become older (John \& Gross, 2004). Third, job tenure was controlled for. Employees who are with an organization for longer expend energy over time and are more likely to experience burnout (Zohar, 1997). Fourth, hours worked per week were controlled for, as the amount of hours an individual works may be a boundary condition that interferes with the time they spend recovering from work and may also impede their well being. Fifth, emotional workload, or the frequency in which one is confronted with emotionally demanding situations at work (van Veldhoven \& Meijman, 1994), was controlled for. The inclusion of emotional 
workload was to rule out one alternative hypothesis in the current model. This alternative hypothesis would state that the corrections officers' fluctuations in strain and recovery experiences would be associated with feeling their work was emotionally demanding, rather than what type of emotion regulation they use. Cronbach's alpha for the scale was .90 .

In addition to these control variables, correlations between the study variables and the other demographic variables included in the survey (i.e., marital status, ethnicity, education, number of children living in the house, minutes spent commuting each day, facility, security level of facility, shift, tenure at facility, veteran status) were examined to determine if the correlations were high enough to warrant including them in the analyses. However, none of these additional demographics were correlated with the study variables higher than $r=.15$, and thus they were not included in the final analyses. 


\section{Chapter 3 \\ Results}

Table 1 shows means, standard deviations, reliabilities, and intercorrelations of all study variables. Appendix J shows the means of the study variables, separated by facility.

\section{Hypothesis Testing: Direct Effects}

To test Hypothesis 1 (i.e., emotion regulation was associated with strain), a series of 6 hierarchical regression models were specified. Specifically, control variables (i.e., age, gender, tenure, hours worked) were entered into the first step of the regression equation, followed by emotional workload entered in the second step, followed by each of the emotion regulation strategies (i.e., reappraisal, suppression) entered into the third and fourth steps of the regression equation predicting each strain outcome (i.e., exhaustion, disengagement, and psychological distress). Results revealed reappraisal predicted disengagement $\left(\Delta R^{2}=.01, F(1,696)=10.10, p<.01\right)$, exhaustion $\left(\Delta R^{2}=.03\right.$, $F(1,697)=28.43, p<.01)$, and psychological distress $\left(\Delta R^{2}=.02, F(1,658)=21.19, p\right.$ $<.001)$. Suppression predicted disengagement $\left(\Delta R^{2}=.03, F(1,696)=22.75, p<.001\right)$, exhaustion $\left(\Delta R^{2}=.03, F(1,696)=31.54, p<.001\right)$, and psychological distress $\left(\Delta R^{2}=.01\right.$, $F(1,657)=1.80, p<.01)$. The results indicated that reappraisal was significantly and negatively related to strain, and suppression was significantly and positively related to strain. Thus, Hypothesis 1 was supported. Table 2 and Table 3 show the results of these analyses.

To test Hypothesis 2 (i.e., emotion regulation was associated with recovery experiences), a series of 6 hierarchical regression models were specified using the same 
steps as above. Results revealed reappraisal predicted psychological detachment $\left(\Delta R^{2}\right.$ $=.06, F(1,697)=48.99, p<.001)$, relaxation $\left(\Delta R^{2}=.06, F(1,697)=50.93, p<.001\right)$, and mastery $\left(\Delta R^{2}=.09, F(1,697)=70.32, p<.001\right)$. Though suppression did not predict psychological detachment $\left(\Delta R^{2}=.00, F(1,697)=2.51, p=.11\right)$, it did predict relaxation $\left(\Delta R^{2}=.02, F(1,697)=13.24, p<.001\right)$ and mastery $\left(\Delta R^{2}=.01, F(1,697)=11.18, p\right.$ $<.01)$. Reappraisal was significantly and positively related to recovery experiences in all models, and suppression was significantly and negatively related to recovery experiences in 2 of the 3 models. Results indicate that Hypothesis 2 was partially supported. Table 4 and Table 5 show the results of these analyses.

To test Hypothesis 3 (i.e., recovery experiences were associated with strain), a series of 9 hierarchical regression models were specified using the same steps as above, with the exception that emotion regulation was not included. After the control variables were entered into the model, psychological detachment did not predict disengagement $\left(\Delta R^{2}=.00, F(1,699)=2.72, p=.10\right)$, psychological detachment did predict exhaustion $\left(\Delta R^{2}=.10, F(1,699)=116.94, p<.001\right)$ and psychological distress $\left(\Delta R^{2}=.06, F(1,660)\right.$ $=58.28, p<.001)$. Relaxation predicted disengagement $\left(\Delta R^{2}=.03, F(1,699)=23.34, p\right.$ $<.001)$, exhaustion $\left(\Delta R^{2}=.15, F(1,699)=177.37, p<.001\right)$, and psychological distress $\left(\Delta R^{2}=.12, F(1,660)=123.90, p<.001\right)$. Finally, mastery predicted disengagement $\left(\Delta R^{2}\right.$ $=.06, F(1,699)=50.11, p<.001)$, exhaustion $\left(\Delta R^{2}=.13, F(1,699)=151.38, p<.001\right)$, and psychological distress $\left(\Delta R^{2}=.08, F(1,660)=75.09, p<.001\right)$. Recovery experiences were nearly uniformly, negatively related to strain. Results indicate that Hypothesis 3 was partially supported. Table 6 , Table 7 , and Table 8 show the results of these analyses. 


\section{Mediation Testing}

To test Hypothesis 4 (i.e., recovery experiences partially mediate the relationship between emotion regulation and strain), I used Baron \& Kenny's (1986) four-step approach to mediation testing. If all of the 4 steps are successfully completed it is concluded that a mediation is present. This approach tests whether a predictor (X) influences an outcome (Y) through a mediator (M). Step 1 (i.e., X predicting Y) was supported by the models in Hypothesis 1. Step 2 (i.e., X predicting M) was supported by the models in Hypothesis 2. Step 3 (i.e., M predicting Y) was supported by the models in Hypothesis 3. To test Step 4 (i.e., X predicting Y, controlling for M), A series of 9 hierarchical regression models were used to examine 18 possible mediation models. Specifically, in a model predicting strain, in step 1, control variables were entered, followed by emotional workload in step 2 , followed by each of the emotion regulation strategies (i.e., reappraisal, suppression) entered into the third and fourth steps of the regression equation, and lastly followed by the recovery experience being tested as a mediator. The value of $\beta$ for the recovery experience in the final step of each model was examined to see if it was significant at $\alpha=.05$. A non-significant $\beta$ indicated that the recovery experience fully mediated the relationship between the emotional regulation and the strain. If the value of $\beta$ was significant in Step 4 , but the value of $\beta$ was lower than it was in the corresponding model in Step 1, this was evidence for a partial mediation. In addition, past literature has encouraged the use of Sobel tests to supplement the Baron and Kenny (1986) mediation testing procedure (Sobel, 1982; Wood, Goodman, Beckmann \& Cook, 2008). The Sobel test is a significance test of a simple mediation that 
tests the difference between the total effects and the direct effect in the model. Table 9 shows a summary of the results of the mediation analyses.

Results indicated that Hypothesis 4 was partially supported. Of the 18 possible mediations examined, 1 full mediation was found, 12 partial mediations were found, and 5 mediations received no support or could not be tested because they did not meet one of the criteria for mediation according to Baron \& Kenny (1986).

Psychological detachment did not mediate the relationship between reappraisal and exhaustion $(\beta=-.09, t(696)=-2.99, p<.001$; Sobel $=-1.06, p=.29)$, but psychological detachment partially mediated the relationship between reappraisal and psychological distress $(\beta=-.10, t(657)=-2.74, p<.01 ;$ Sobel $=-5.13, p<.01)$.

Disengagement was not evaluated as an outcome, as the relationship between detachment and disengagement was found to be not significant in Hypothesis 3. Additionally, psychological detachment was not tested as a mediator in the relationship between suppression and strain because psychological detachment was not significantly related to suppression in Hypothesis 2. Overall, psychological detachment was a partial mediator in 1 of the 6 proposed models.

Relaxation was a significant partial mediator in all of the 6 models in which it was tested as a mediator. Relaxation partially mediated the relationship between reappraisal and disengagement $(\beta=-.08, t(696)=-3.86, p<.05$; Sobel $=-4.26, p<.01)$, exhaustion $(\beta=-.08, t(696)=-2.54, p<.05 ;$ Sobel $=-6.32 p<.01)$, and psychological distress $(\beta=-$ $.07, t(657)=-1.97, p<.05 ;$ Sobel $=-6.04 p<.01)$. Additionally, relaxation partially mediated the relationship between suppression and disengagement $(\beta=.16, t(696)=4.25$, 
$p<.01 ;$ Sobel $=2.96, p<.01)$, exhaustion $(\beta=.13, t(696)=4.47, p<.01 ;$ Sobel $=3.45, p$ $<.01)$, and psychological distress $(\beta=.07, t(657)=2.08, p<.05$; Sobel $=3.40 p<.01)$.

Mastery was a partial or full mediator in all of the 6 models in which it was tested as a mediator. Mastery fully mediated the relationship between reappraisal and disengagement $(\beta=-.05, t(696)=-1.25, p=.21)$, and partially mediated the relationships between reappraisal and exhaustion $(\beta=-.07, t(696)=-2.21, p<.05$; Sobel $=-6.92 p$ $<.01)$ and psychological distress $(\beta=-.08, t(657)=-2.29, p<.05$; Sobel $=-6.01 p<.01)$. Additionally, mastery partially mediated the relationship between suppression and disengagement $(\beta=.15, t(696)=4.08, p<.01 ;$ Sobel $=3.01 p<.01)$, exhaustion $(\beta=.14$, $t(696)=4.66, p<.01 ;$ Sobel $=3.20 p<.01)$, and psychological distress $(\beta=.09, t(657)=$ $2.47, p<.01 ;$ Sobel $=3.10 p<.01)$.

\section{Analyses of Research Questions}

To examine Research Question 1, 2, and 3, which examined whether coping strategies moderate the relationships between emotion regulation, recovery experiences, and strain, hierarchical regression analysis was conducted. To alleviate issues with multicollinearity, interaction terms were created using the product of centered predictors (i.e., emotion regulation and recovery experiences) and moderators (i.e., coping strategies).

Specifically, to test Research Question 1 [i.e., coping (venting, seeking emotional social support) moderated the relationship between emotion regulation (reappraisal, suppression) and recovery experiences (psychological detachment, relaxation, mastery)], a series of 12 regression models were tested. In Step 1 of the hierarchical regression, 
control variables (i.e, age, gender, tenure, hours worked) were entered as predictor variables, and the outcome (i.e., recovery experiences) was entered as a dependent variable. In Step 2, emotional workload was entered as a control variable. In Step 3, the centered predictor variables were entered. In Step 4, the interaction term was entered as a predictor variable. Of these 12 models, 1 was significant. In the final step of the regression, the interaction between suppression and emotional social support explained significant incremental variance in psychological detachment $\left(\Delta R^{2}=.03, F(2,697)=\right.$ $13.69, p<.001)$. Figure 2 presents a graphical representation of this interaction. A test of simple slopes suggested neither the slope of low emotional social support $(\mathrm{t}=.51, \mathrm{p}=.61)$ and slope for high emotional social support were significant $(\mathrm{t}=1.81, \mathrm{p}=.07)$. In other words, although the interaction term predicted incremental variance in the model, neither of the slopes for high or low levels of the moderator were significantly different from zero.

To test Research Question 2 [i.e., coping moderated the relationship between emotion regulation and strain (disengagement, exhaustion, psychological distress)], a series of 12 regression models were tested. In step 1 of the hierarchical regression, control variables (i.e, age, gender, tenure, hours worked) were entered as predictor variables, and the outcome (i.e., strain) was entered as a dependent variable. In Step 2, emotional workload was entered as a control variable. In Step 3, the centered predictor variables were entered. In Step 4, the interaction term was entered as a predictor variable. Of these 12 models, 2 were significant. The interaction between suppression and venting explained significant incremental variance in disengagement $\left(\Delta R^{2}=.02, F(1,697)=\right.$ 
$17.86, p<.001)$ and exhaustion $\left(\Delta R^{2}=.01, F(1,697)=7.92, p<.01\right)$. Figure 3 and Figure 4 present graphical representations of these interactions. For disengagement, a test of simple slopes suggested that the slope for individuals low in venting was significant $(\mathrm{t}$ $=8.32, \mathrm{p}<.001)$, and the slope for individual high in venting was significant $(\mathrm{t}=2.50, \mathrm{p}$ $<.05)$. For exhaustion, a test of simple slopes suggested that the slope for individuals low in venting was significant $(t=6.67, \mathrm{p}<.001)$, and the slope for individuals high in venting was significant $(\mathrm{t}=2.81, \mathrm{p}<.05)$.

To test Research Question 3 (i.e., coping moderated the relationship between recovery experiences and strain), a series of 18 regression models were tested. In step 1 of the hierarchical regression, control variables (i.e., age, gender, tenure, hours worked) were entered as predictor variables, and the outcome (i.e., strain) was entered as a dependent variable. In Step 2, emotional workload was entered as a control variable. In Step 3, the centered predictor variables were entered. In Step 4, the interaction term was entered as a predictor variable. Of the 18 models, none were significant.

Post-hoc analyses. To adjust for family-wise error inflating Type 1 error, a Bonferroni type adjustment was applied to the significance criterion (i.e., $\alpha=.05$ ). Bonferroni-type adjustments create a more conservative significance criterion to account for the increase in Type 1 error (Tabachnick \& Fidell, 2007) by dividing the significance criterion by the number of dependent variables within each family. In the current study, there are two families of dependent variables - recovery experiences and strain - with three items in each group. Thus, each regression model was evaluated at a different significance criterion $(\alpha=.05 / 3=.02)$ to account for the inflation in Type 1 error. 
Overall, correcting for Type 1 error inflation using a Bonferroni adjustment had no effect on the findings of the hypotheses or research questions.

\section{Additional Analyses: Negative Affectivity}

Job stress researchers have debated the role of negative affectivity in self-reports of workplace stressors and strains (e.g., Spector, Zapf, Chen, \& Frese, 2000). In the analyses described above, negative affectivity was not included as a control variable. One reason for this was its high correlation with emotional workload $(r=.56)$, which was also used as a control variable. Another reason for not including negative affectivity was that including it may unnecessarily partial out variance that is substantively important to the study variables (Spector et al., 2000). For instance, suppression has been associated with negative affectivity (Gross \& John, 2003), and controlling for negative affectivity may remove the effect of suppression on strain. In other words, part of the construct of suppression may indeed be negative affectivity. However, all of the analyses were also run while including negative affectivity as an additional control variable. Overall, the results of the analyses were not substantially affected.

\section{Additional Analyses: Interaction Between Reappraisal and Suppression}

It may be possible that individual emotion regulation strategies interact with each other in their prediction of strain and recovery experiences. For instance, individuals may use varying levels of reappraisal and suppression, and depending on the relationship between these strategies, one might experience different outcomes. To explore this further, the interaction between reappraisal and suppression was examined to see if this interaction explained incremental variance above the effects of either reappraisal or 
suppression. A series of moderated regression analyses were conducted to see if this interaction was associated with strain or recovery experiences. However, the interaction term did not produce a significant $\Delta R^{2}$ in any of the models. This finding is discussed in some detail in the discussion. 


\section{Chapter 4 \\ Discussion}

The current study aimed to examine whether emotion regulation at work was associated with strain through the influence of nonwork recovery experiences within the corrections occupation. Through this research, the study attempted to examine previously unexamined correlates of strain among corrections officers, while simultaneously adding to the existing research on emotion regulation at work, nonwork recovery experiences, and occupational burnout.

Generally, the results supported the proposed relationships between emotion regulation, recovery experiences, and strain. Specifically, I proposed that reappraisal would be associated with lower levels of disengagement, exhaustion, and psychological distress, while suppression would be associated with higher levels of these strain indicators. Reappraisal appeared to have consistently negative associations with strain, while suppression appeared to be consistently positively associated with strain. These findings are consistent with existing research on emotion regulation that has found reappraisal and suppression to be oppositely associated with a variety of outcomes, including strain (Gross \& John, 2003). This evidence is in support of the theoretical underpinnings of emotion regulation strategies (Gross, 1998) that suggest that reappraisal can be a less effortful strategy and subsequently is associated with more positive intrapersonal and interpersonal outcomes, while suppression is resource-depleting and is associated with strain. 
Interestingly, these findings also suggest there may be utility in measuring specific emotion regulation strategies in the workplace. Overall, suppression was associated with strain, which is consistent with meta-analytic findings on emotion regulation strategies similar to surface acting (Hülsheger \& Schewe, 2011). However, reappraisal was negatively associated with strain and these relationships had effect sizes similar to those observed between suppression and strain. This finding may be explained by the gain-spiral described by COR theory (Hobfoll, 1989), in which reappraisal conserves more resources than suppression. These resources may then be used to gain additional resources and protect individuals from strain. Additionally, this supports the utility of the recent call by Hülsheger and Schewe (2011) to assess specific emotion regulation strategies rather than global measures of emotional labor in order to observe which specific strategies may have negative relationships with strain.

I also proposed that reappraisal would be positively associated with recovery experiences, and suppression would be negatively associated with recovery experiences. Findings indicated that reappraisal predicted higher levels of recovery experiences, while suppression predicted lower levels of recovery experiences. This is consistent with the small number of studies on recovery experiences that have found significant relationships between emotional stressors and recovery experiences (e.g., Sonnentag \& Grant, 2012; Sonnentag et al., 2010). These findings suggest that reappraisal may be associated with reduced activation of psychobiological systems and enough resources to participate in hobbies outside of work, both of which are associated with improved ability to engage in recovery experiences. Similarly, suppression may be associated with over-activated 
internal systems, and could drain more personal resources from the individual, which could be associated with a reduced capacity for recovery experiences.

Contrary to my expectations, suppression was not significantly associated with psychological detachment. At first glance, this finding may be in opposition to the evidence that suppressing emotions during the day may be associated with subsequent ruminative thoughts about these emotions or their associated events (Gross \& John, 2003). Though psychological detachment, or mentally disengaging from work, and rumination, or repetitive unconstructive thought (Watkins, 2008), are related constructs, recent research suggests they are distinguishable (Eby \& Laschober, 2013). It may be possible that suppressing emotions at work still allows for psychological detachment during nonwork hours as individuals try to recover from work. Ruminative thinking may occur, but it was not directly assessed in the study and therefore this is purely speculative.

The current study found that recovery experiences (psychological detachment, relaxation, and mastery) were associated with reduced disengagement, exhaustion, and psychological distress symptoms, with the sole exception that psychological detachment did not predict disengagement. These findings are consistent with research that has determined nonwork recovery experiences as influential in affecting employee strain (e.g., Sonnentag et al., 2008). Interpreting these findings through the lens of COR theory (Hobfoll, 1989), nonwork recovery experiences may provide opportunities for employees to replenish the resources that are lost during the workday, and engaging in these experiences is associated with resource-gain and lessened strain as a result. One possible explanation for the nonsignificant relationship between psychological detachment and 
disengagement is that being thoroughly engaged in one's job may not permit an individual to either detach or even experience feelings of disengagement, even when exposed to chronic workplace stressors.

With the significant relationships described above, support was also found for a partial mediation in which emotion regulation was associated with strain through recovery experiences. Relaxation and mastery experiences appeared to be the more salient nonwork recovery experiences in this study. Relaxation partially mediated the relationships between reappraisal and all strain indicators, and suppression and all strain indicators, thus mediating all six models in which it was tested as a mediator. Mastery was a full mediator in the relationship between reappraisal and disengagement, and partially mediated the five other models in which it was included. Psychological detachment mediated the relationship between reappraisal and psychological distress, but did not mediate any other model. These findings largely support the proposed model such that reappraisal is positively associated with recovery experiences (relaxation, mastery), and that in turn recovery experiences are negatively associated with strain; oppositely, that suppression is negatively associated with recovery experiences, and that in turn recovery experiences are negatively associated with strain. However, these findings should be cautiously interpreted as the current data are cross-sectional and therefore do not lend support for claims of causality.

These results are consistent with the proposition that certain recovery experiences are at least one vital mechanism to explain the relationship between job stressors and employee health (Geurts and Sonnentag, 2006; Kinnunen et al., 2011). Furthermore, they 
add to recent empirical findings that indicate recovery experiences appear to mediate the stressor-strain relationship (Kinnunen et al., 2011). The findings indicate recovery experiences are mainly partial, but not full, mediators, also are consistent with the theoretical rationale that suggests emotion regulation affects strain through other mechanisms, including an increased sense of inauthenticity (John \& Gross, 2004), or the depletion of some limited resource (Baumeister et al., 1998). Though recovery experiences may not be the only mediator in these relationships, it does appear that they may at least partially explain the influence on employee strain.

Additionally, this study examined emotion-focused coping strategies to determine if individual differences in coping with stress moderated relationships between the study variables. The study focused on emotion-focused coping on the basis of the "matching hypothesis" in work stress research (e.g., de Jonge \& Dormann, 2006), which states that moderations are likely to be found when the stressor, strain, and moderator share similar characteristics. Several interactions were found to be significant, but many of the tested relationships were not. Two of these interactions appear to suggest the combination of low suppression and low venting may have the most positive relationship with burnout, but this conclusion may be premature due to the great number of models involving these variables that were not significant.

Taken together, the results suggest that in this particular study the coping strategies that were examined did not significantly moderate the relationships between emotion regulation, recovery experiences, and strain. Interestingly, the direct relationships between coping and strain and coping and recovery experiences indicate 
emotion-focused-coping is not strongly related to the outcomes in this sample. Venting had low, positive relationships with disengagement, exhaustion, and psychological distress ( $r$ ranged .07 to .15$)$, and had almost no relationship with recovery experiences $(r$ ranged .00 to .03$)$. Seeking emotional social support had low to moderate negative relationships with disengagement, exhaustion, and psychological distress ( $r$ ranged from .17 to -.24 ) and moderate, positive relationships with recovery experiences ( $r$ ranged .22 to .31$)$.

\section{Contributions}

The current study contributes to the literature on emotion regulation, recovery from work, and employee strain in several ways. First, this study is the first research I am aware of that directly examines the relationship between emotion regulation at work and nonwork recovery experiences. This study has gone a step further than recent research (Sonnentag \& Grant, 2012; Sonnentag et al., 2010) by including multiple recovery experiences and two emotion regulation strategies in the analysis of this relationship, while also controlling for emotional workload. Although research has steadily accumulated attesting to the role of recovery from work in employee strain, few studies so far have taken the perspective of examining predictors of such recovery experiences. The initial findings of this study indicate a possible relationship between emotion regulation at work and recovery experiences and in doing so takes into account the research on the importance of emotions in organizations and extends findings in support of the importance of nonwork recovery experiences. 
This study further contributes to past literature by systematically assessing previously unexamined correlates of strain outcomes within the corrections occupation. Most research examining stress and strain in corrections officers has examined typical workplace factors (i.e., supervision, job variety; Lambert et al., 2012) and found mixed results between these factors and burnout. By studying psychosocial factors that may be associated with strain among corrections officers, this research adds to a growing number of studies that have shifted the focus of job stress research to focus on factors affecting mental health in the workplace (e.g., LaMontagne, D’Souza, \& Shann, 2012). Though researchers have acknowledged emotion regulation is likely important for corrections officers, few have actually assessed it (exception: Nylander et al., 2011). Additionally, organizational psychology studies of workplace strain have rarely been conducted using corrections officers (exceptions: Dollard \& Winefeld, 1998; Rutter \& Fielding, 1988), and the results of the study provide opportunities for future research and interventions in this occupation.

Finally, the results regarding emotion regulation strategies and strain add to the understanding of how emotional labor is associated with employee strain. The results of this study demonstrated initial evidence for a strategy (i.e., reappraisal) that may benefit employees who utilize it at work. While research on emotional labor has turned up mixed results regarding regulating emotions through deep acting, this study is evidence for the importance of measuring specific strategies rather than global measures (Hülsheger \& Schewe, 2011). By measuring a specific emotion regulation strategy rather than a global measure of emotional labor, results indicated consistent, strong relationships between 
reappraisal and both strain and recovery experiences. Future research should continue to examine reappraisal as a useful workplace emotion regulation strategy and attempt to replicate and expand the current research, for example by using longitudinal research designs. A focus on specific strategies may additionally help to alleviate the construct problem that has been present in research on emotion regulation in the workplace (Hülsheger \& Schewe, 2011).

Interestingly, additional analyses indicated that reappraisal and suppression did not interact to predict strain or recovery experiences. While it may be that individuals may use a variety of strategies at work (Diefendorff et al., 2008) to regulate their emotions, researchers tend to find that individuals regulate their emotions similarly across situations (Gross \& John, 2003). Researchers have theorized that individuals tend to either suppress or reappraise emotions, in a manner characteristic of a personality-like trait, and the findings of the current study support this (Gross \& John, 2003). The findings at the between-person level gave no indication that meaningful differences exist between individuals who vary in their use of both reappraisal and suppression.

\section{Limitations and Directions for Future Research}

The results of the current study should be interpreted while considering the strengths and limitations of the research design. First, the data were cross-sectional and thus findings of the study cannot provide conclusive evidence that recovery experiences mediate the proposed relationships, as mediation implies a process that occurs over time. Therefore, explanations of reverse-causation relationships cannot be ruled out. For instance, it is possible individuals low in strain may be more likely to use reappraisal at 
work rather than suppression, and that individuals high in recovery experiences are also more likely to use reappraisal than suppression. However, the significant results that were found for several mediation models suggests that the proposed model might be conceptually accurate, but that it should be tested using a longitudinal design. Also, the direction of the examined relationships between emotion regulation and strain has been supported in longitudinal research, while the reverse pathways were not supported (Hülsheger, Lang, \& Maier, 2010). Still, more longitudinal research is needed to examine the causal direction of the proposed model in the current study.

One particular area that future longitudinal research can help to address is to identify the type of factors that may precede reappraisal at work. These factors individual or organizational - may hinder or promote employee reappraisal at work, and identifying them is important for future workplace interventions. For instance, it is possible that employees may need to start the workday with enough resources (i.e., energy, mood) to successfully reappraise situations throughout the day. Although reappraisal is thought to be a trait-like phenomenon, at least one study found that employees who felt greater fatigue at work were more likely to hide their feelings at work at a later shift (Beal, Trougakos, Weiss, \& Dalal, 2013). Another possibility is that organizational factors, such as a climate or culture that allows for discussion of emotionally-demanding events, are more supportive of reappraisal than a climate in which employees are not supported in this way. One inviting avenue of research would require assessing the climate of different corrections facilities using hierarchical linear modeling to determine if certain facilities with more supportive climates, for instance, 
were associated with greater levels of employee reappraisal. Future studies should be designed to evaluate several possible predictors of reappraisal at work to determine what contributes to reappraisal and what factors may hinder it.

Second, self-report data may enhance common-method bias (Podsakoff, Mackenzie, Lee, \& Podsakoff, 2003) and increase correlations between study variables. Therefore, it is possible in the current research that the reported effect sizes are inflated and in reality may be smaller. Future research should incorporate, for example, spouse- or other-reports. Spouse-reports may be especially valuable in the current occupation to gather information on strain, and would provide an outcome for comparison with the selfreport measures. This could also work to counteract any social desirability that may influence participants to respond in a certain way to survey questions. Future research should also integrate the use of objective health data, such as blood pressure. Evidence suggests that objective health measures of cardiovascular health are associated with subjective strain (e.g., Ilies, Dimotakis, \& Watson, 2010; Wright, Cropanzano, Bonett, \& Diamond, 2009), and using these type of measures would further combat the welldocumented biases of self-report data.

Third, the survey methodology used asked participants to respond in general and did not capture events that occur on a daily level. Especially for emotion regulation strategies, studies that incorporate ESM could further explore whether a single event in which emotions are regulated at work could predict how strain unfolds throughout the day. For instance, a corrections officer who generally reappraises their emotions when faced with a stressful situation may report high levels of using reappraisal. However, one 
intense confrontation with an inmate in which they must suppress their feelings could have a more meaningful effect on strain than the aggregated effect of the majority of their encounters during the workday. Furthermore, recent research has suggested that suppression, when combined with empathy, may be an effective regulation strategy in times of crisis at work (Thiel, Connelly, \& Griffith, 2013). Studies using one measurement point in time may not capture the dynamic and complex aspect of emotion regulation at the event-level, and as such future research should continue to examine event-based or daily relationships involving emotion regulation.

Fourth, the research questions in this study examined only emotion-focused coping strategies. Problem-focused strategies were not included in the proposed analyses, based on the matching hypothesis that has been supported in past research (de Jonge \& Dormann, 2006). It was reasoned that emotion regulation was an emotional stressor that likely required emotion-focused coping. However, it is possible that problem-focused coping strategies are more salient in the current sample. Emotional social support was moderately correlated with being female $(r=.27)$, but the majority of the sample $(88 \%)$ was male. This type of coping strategy may not be as relevant to employee strain given the characteristics of the corrections occupation. Also, as the research on emotionfocused coping has uncovered mixed findings regarding the utility of these coping strategies (Stanton \& Low, 2012), it may be that the two strategies chosen for analyses in the current research may not be useful for corrections officers. Therefore, the results do not discount the role of coping in the current research, but rather are contradictory to recent research that has indicated the utility of emotion-focused coping (de Ven et al., 
2013). Future research should therefore examine the role of problem-focused coping strategies in corrections. Problem-focused coping may have greater utility for corrections officers who believe they can take action to address their source of strain. Future studies should also consider additional emotion-focused coping strategies to explore which may be beneficial or maladaptive. For instance, this study assessed whether the officer sought emotional social support and not whether that support was actually available. One suggestion would be to assess whether corrections officers receive this emotional social support. Furthermore, researchers should incorporate different study methodologies (i.e, ESM) and ways of measuring coping strategies (i.e., daily or momentary assessments, coworker reports) to capture the situational and temporal aspects of the coping process.

The results of the current research suggest that both emotion regulation strategies and recovery experiences may be important factors associated with strain among corrections officers. However, the limitations of the current research speak strongly for a need to expand on the research methodology that was used and the constructs that were examined. Researchers should also consider which resources are available to individuals before they engage in emotion regulation. For instance, socio-economic factors may chronically prevent individuals from having adequate resources (i.e., energy) to use reappraisal at work; or, these factors could also affect their attitudes and behaviors they bring to work, making them less able to or willing to regulate their emotions through functionally useful strategies. Furthermore, if researchers do explore this question, they should also attempt to accurately measure these specific resources. As the current study conceptualized recovery experiences as the processes through which individuals gain 
resources (i.e., energy, mood), future studies should define and assess these resources more directly. More research is therefore needed to determine the antecedents to emotion regulation strategies at work and to carefully evaluate the resources individuals have before emotion regulation occurs.

Another limitation is that I was unable to account for supervisory status in the current study. Due to the complex nature of the hierarchy of ranks in the corrections system, and the fact that officers often do not have an assigned 'supervisor,' we did not include a measure capturing whether a participant supervised other corrections officers. This may be an important factor in determining the type of emotion regulation corrections officers engage in, and how often. Research has shown that organizational display rules differ across organizational targets, such as coworkers, supervisors, and clients (Diefendorff \& Greguras, 2009). Therefore, based on how often an employee interacts with coworkers versus clients (in corrections, inmates) and whether they are a supervisor may affect how they regulate emotions at work. Future research should take into account the supervisory status of employees when analyzing emotion regulation strategies. On a similar note, future research should take the target of the emotion regulation into account. For instance, as literature on emotion regulation suggests (Gross, 1998), suppressing emotions when interacting with coworkers and supervisors may be associated with poor interpersonal functioning and higher levels of strain. However, corrections officers have interactions with mentally ill inmates in which suppression may be a more effective strategy. Therefore, future studies should differentiate between 
emotion regulation targets in order to empirically determine whether different strategies are associated with differential outcomes, depending on who the interaction target is.

Another consideration for research is to determine how the results of this study may be specific to this sample; or, in other words, whether the findings could be replicated in other occupations. The question of 'context' may be of particular importance in this study, given the unique occupational characteristics of corrections (Armstrong \& Griffin, 2004). Though the links between emotion regulation and strain, and recovery experiences and strain have already been widely replicated, the relationship between emotion regulation and recovery experiences has not been explored prior to this study. This may raise the question of whether the findings regarding this specific hypothesis may be replicated in other samples, such as white-collar jobs. Of particular interest could be the relationship between suppression and psychological detachment which was not significant in this study. It is possible that, as hypothesized, suppressing emotions during the workday may resurface after one leaves the workplace, if these emotions are the result of relatively mild interpersonal interactions typical of the common office workplace. However, the range of content and emotions that a corrections officer may be suppressing at work is quite possibly of a disturbing nature given the population of inmates they work with. Therefore, correction officers may suppress their emotions at work and continue to suppress them away from work such that they are successfully detaching from work, which could explain the nonsignificant relationship between suppression and detachment. However, this is pure speculation and this relationship 
would need to be empirically examined in other samples before any conclusions are drawn.

\section{Practical Implications}

The findings of this study have several implications for practice. The results support the idea that reappraising emotions at work is associated with positive employee outcomes. Therefore, trainings that teach strategies such as mindfulness could be used to provide corrections officers with a personal resource at work (Allen \& Kiburz, 2012; $\mathrm{Hu} \square$ lsheger, Alberts, Feinholdt, \& Lang, 2013; Wolever et al., 2012). Mindfulness is a state of consciousness in which individuals experience events receptively and in a nonjudgmental fashion, and studies have found mindfulness to be related to lower burnout and higher job satisfaction (Hu $\square$ lsheger et al., 2013). Mindfulness involves four key characteristics: Receptive awareness, pre-conceptual information processing, presentoriented consciousness, and the knowledge that mindfulness is an inherent human capacity that may vary in strength. These four characteristics are the focus and basis for training mindfulness in the workplace (Hu $\square$ lsheger et al., 2013). By teaching individuals that they can change their perception of emotional events, mindfulness can eventually promote using techniques such as reappraisal. Instead of either reacting to a situation or if a reaction is inappropriate for the workplace - suppressing emotions, mindfulness can provide a new paradigm for individuals to use to regulate emotions. Although it appears that individuals tend to either reappraise or suppress emotions as a personal tendency (Gross \& John, 2003), studies on mindfulness in the workplace have demonstrated the utility of these trainings in teaching individuals principles of mindfulness and intervening 
in a way that they may teach individuals to reappraise emotions instead of suppressing emotions while at work. The results of these studies so far have been promising and may be especially relevant in the correctional setting in which high emotional demands characterize the job.

However, when considering implementing mindfulness trainings in a corrections environment, the context of the occupation must be closely scrutinized to determine if existing norms may conflict with the training material. For instance, corrections officers may receive training that stresses the importance of containing one's feelings during a riot or fight between inmates in order to focus on controlling the situation. Effectively, this is suppression, and is likely encouraged either informally, formally in training, or both. Corrections officers may be told to hide their feelings when addressing these violent situations to maintain focus and their safety. Although suppression may be an appropriate strategy in dire circumstances, teaching officers to reappraise rather than suppress may be in direct opposition to their training or informal indoctrination into the occupation. Therefore, it may be necessary for mindfulness trainings to be conducted by someone with explicit knowledge of the job demands of a corrections officer. In this way, the trainer can address the areas in which mindfulness can be applied to the job. Similarly, the trainer may be able to identify how suppressing emotions may be encouraged as part of the culture of corrections before mindfulness training is implemented, and this knowledge may guide their training agenda.

The results also indicated that recovery experiences were strongly, negatively associated with strain. A recent quasi-experimental study found that individuals could 
learn how to organize their off-job time in a manner that facilitates the replenishment of resources that may be drained at work (Hahn, Binnewies, Sonnentag, \& Mojza, 2011). In other words, techniques to best experience recovery can be taught to individuals. In stressful occupations, the knowledge of and ability to successfully recover can aid the employee in protecting against resource loss in the long-term. These type of work-life balance interventions utilize well-supported theories, such as goal-setting theory (Locke \& Latham, 2006), to work with employees to set goals on how to balance their work and family lives. Though this research is in its infancy, it may be especially important for correction personnel to emphasize the importance of recovery time and the concept of work life-balance and implement interventions that support corrections officers' efforts to balance their lives in an effort to reduce strain.

Finally, Occupational Health Psychology (OHP) researchers have suggested that applying a public health model to the workplace and attempting to intervene at a primary level may be the most effective way to improve employee health and reduce strain (Quick, 1999). The current research suggests that emotion regulation may be a stressor in the corrections occupation. Interestingly, although reappraisal and suppression explained incremental variance above and beyond the control variables in employee strain outcomes, emotional workload tended to have the strongest relationship with strain.

The presence of high emotional job demands begs the question of how to intervene at a primary, organizational level in order to reduce the need for employees to regulate emotions. Several suggestions may be in order. In corrections, it may be worthwhile to institute a policy that somehow allows an officer to temporarily 'clock out' 
after a particularly emotion-eliciting situation. This specific type of 'work break' could provide a resource to officers and help them feel better equipped to manage the emotional demands of the job, especially after a critical emotional incident. Also, given the high levels of burnout and psychological distress, policy-makers should consider integrating flexible schedules into corrections. Although corrections is a unique occupation in that a certain number of officers must be present to ensure the safety of the facility, for example, this coverage could still be accomplished with a flexible working schedule that allows officers to switch shifts with their colleagues. This type of flexibility can provide employees with a greater sense of control over their work, which can protect them from feelings of uncertainty that may contribute to strain and may make it easier to balance work and family demands. Another avenue for intervention would be through a comprehensive job design intervention. This would involve making changes to the way the work of a corrections officer is organized and how the demands of their job are met. If done, this should involve a systematic job analysis to determine what type of tasks corrections officers are required to do that may be particularly stressful but are not tasks central to keeping the facility safe. In this case, tasks that are emotionally demanding could be adjusted by changing how they are completed. Finally, the corrections occupation may be ripe for a culture change given the high number of injuries, fatalities, and high levels of strain (NORA, 2013). This type of the culture adjustment that promotes the recognition of the emotional nature of the job and provides support for emotional demands would be a slow process. However, identifying aspects of the culture that are embedded in the profession and targeting a few aspects that are unhelpful for 
dealing with emotional demands could be the first step for researchers and practitioners to work towards reducing future safety and stress concerns that currently characterize the occupation.

\section{Conclusion}

The current study examined relationships between emotion regulation at work, recovery experiences, and strain in corrections officers. Specifically, results indicate that reappraisal at work is positively associated with recovery experiences, which in turn are associated with decreased strain. In contrast, suppression is negatively associated with recovery experiences, and lower levels of recovery in turn are positively associated with strain. As researchers work towards understanding factors that may contribute to the negative outcomes observed in the corrections occupation (Obidoa et al., 2011; Spinaris \& Denhof, 2011; Stack \& Tsoudis, 1997), this study identifies emotion regulation and nonwork recovery experiences as possible influences of employee strain that warrant further attention. These data mark a step towards generating organizational-level interventions that could address the overall health and psychological strain of corrections officers and provide an avenue for protecting corrections officers from strain. 


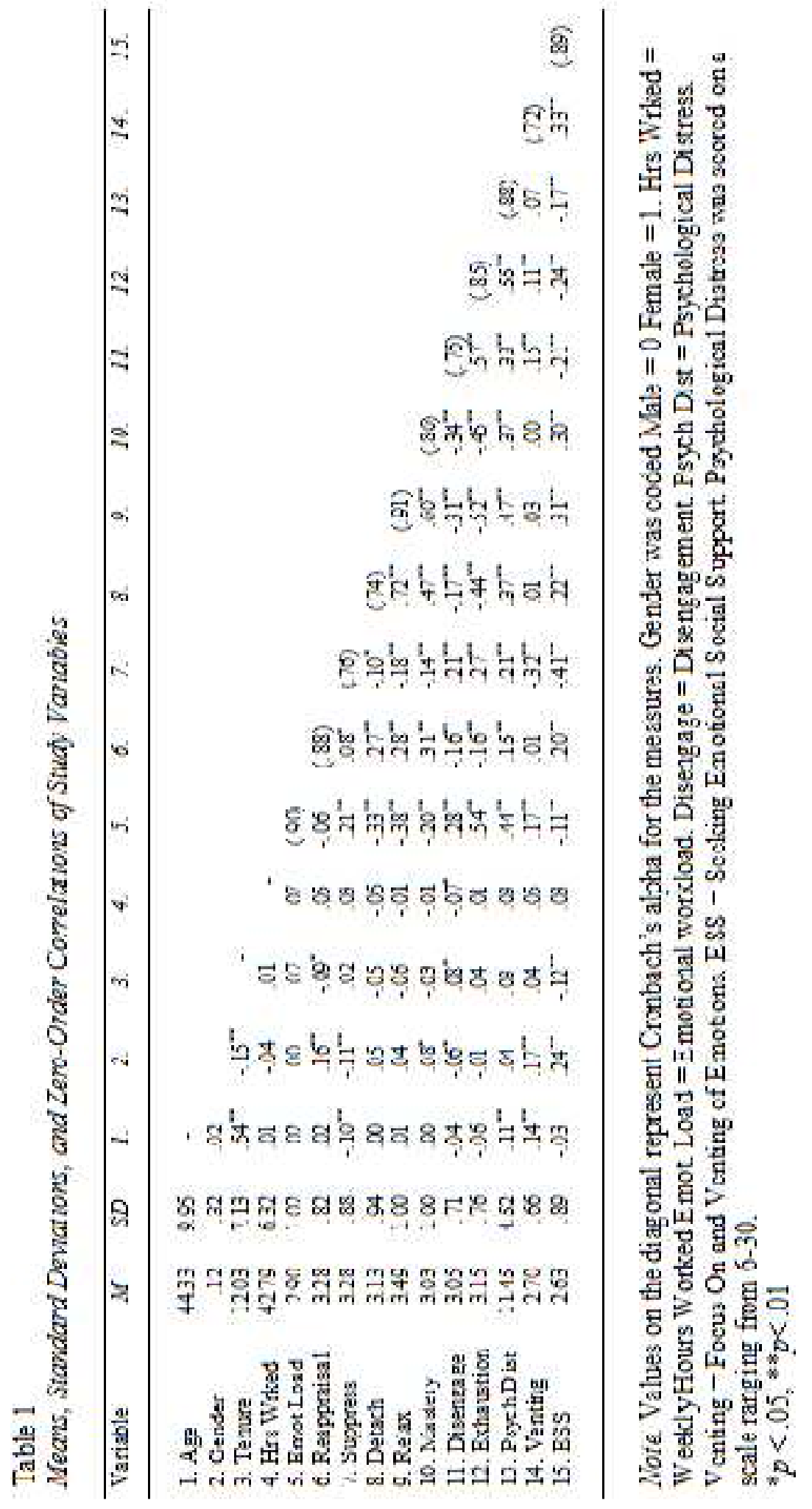




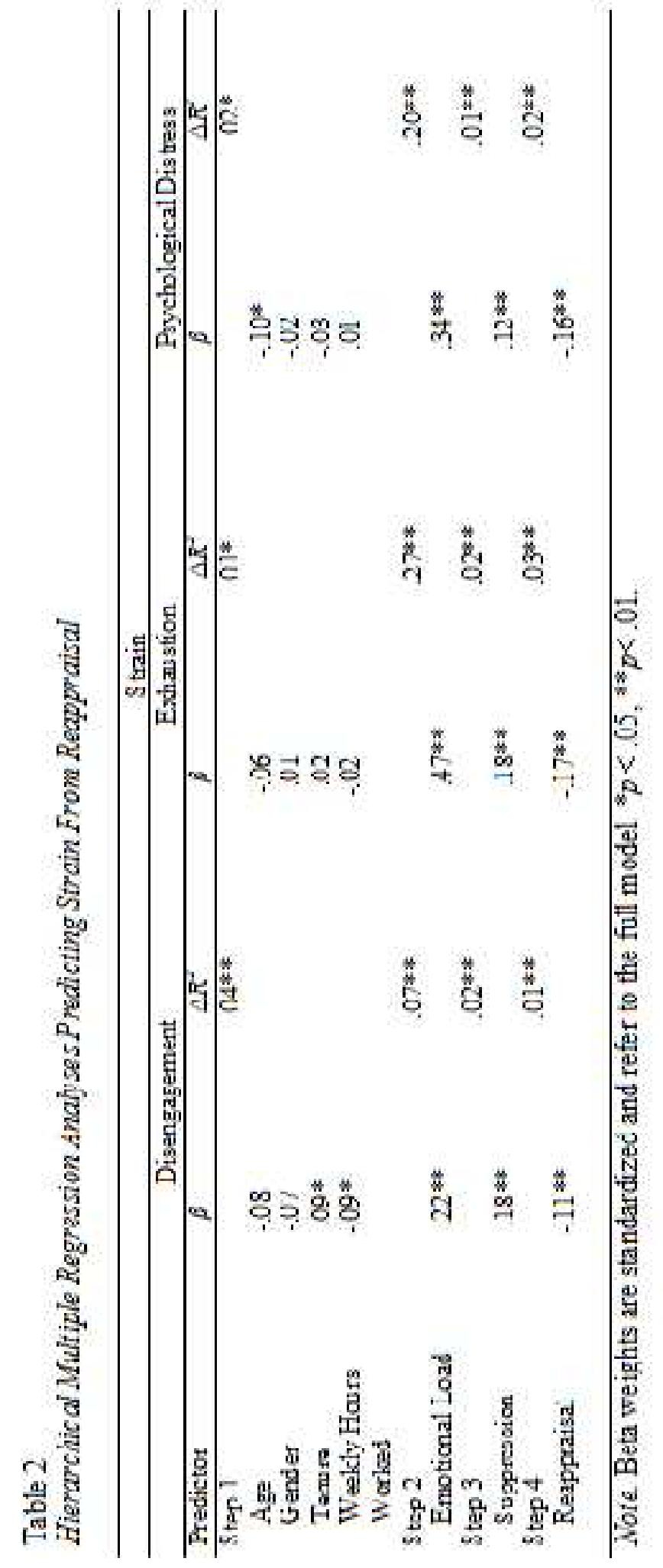




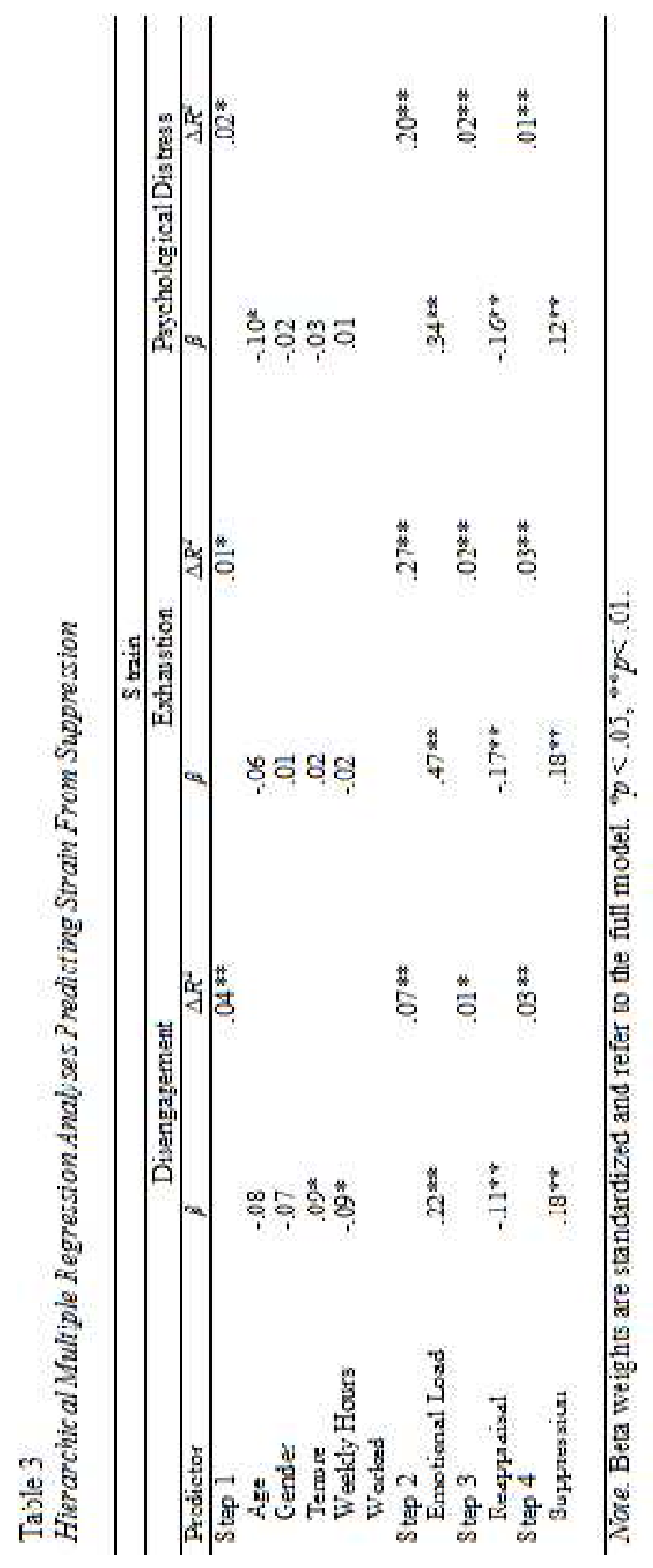




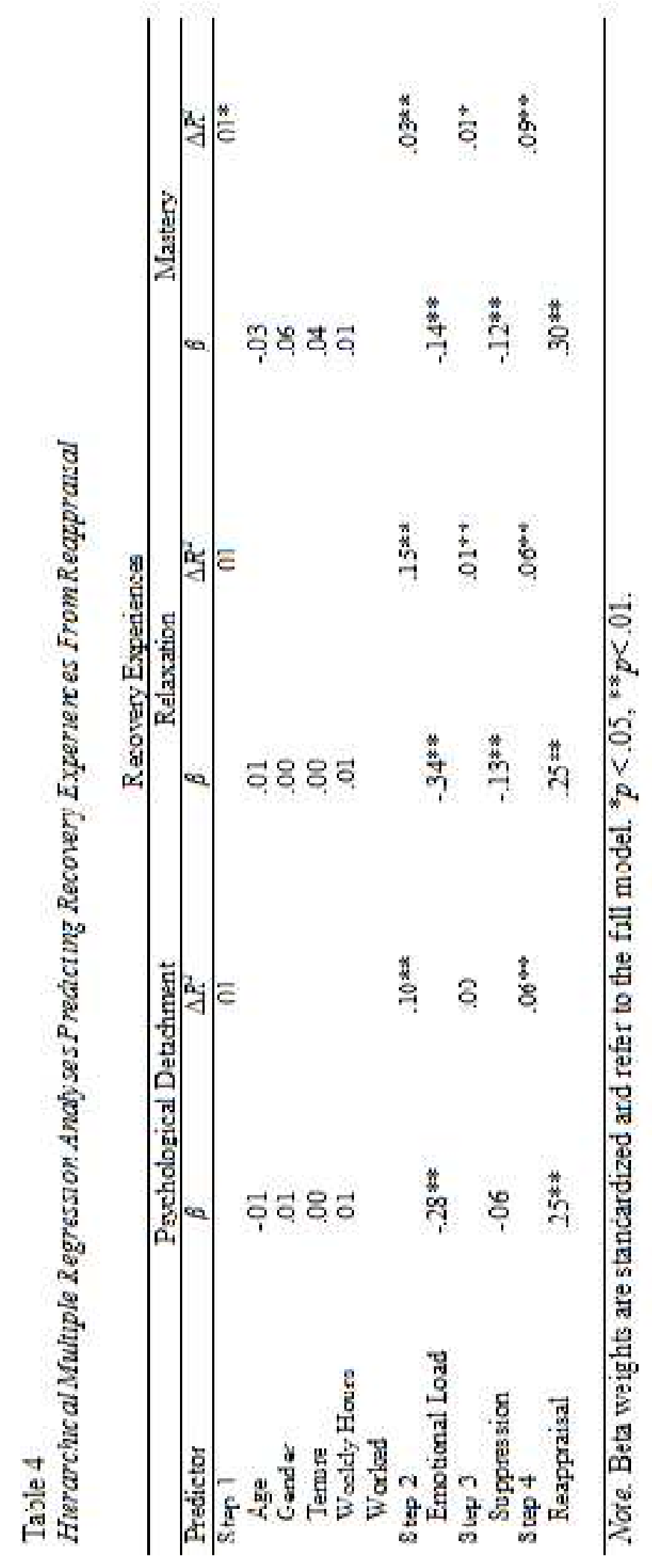




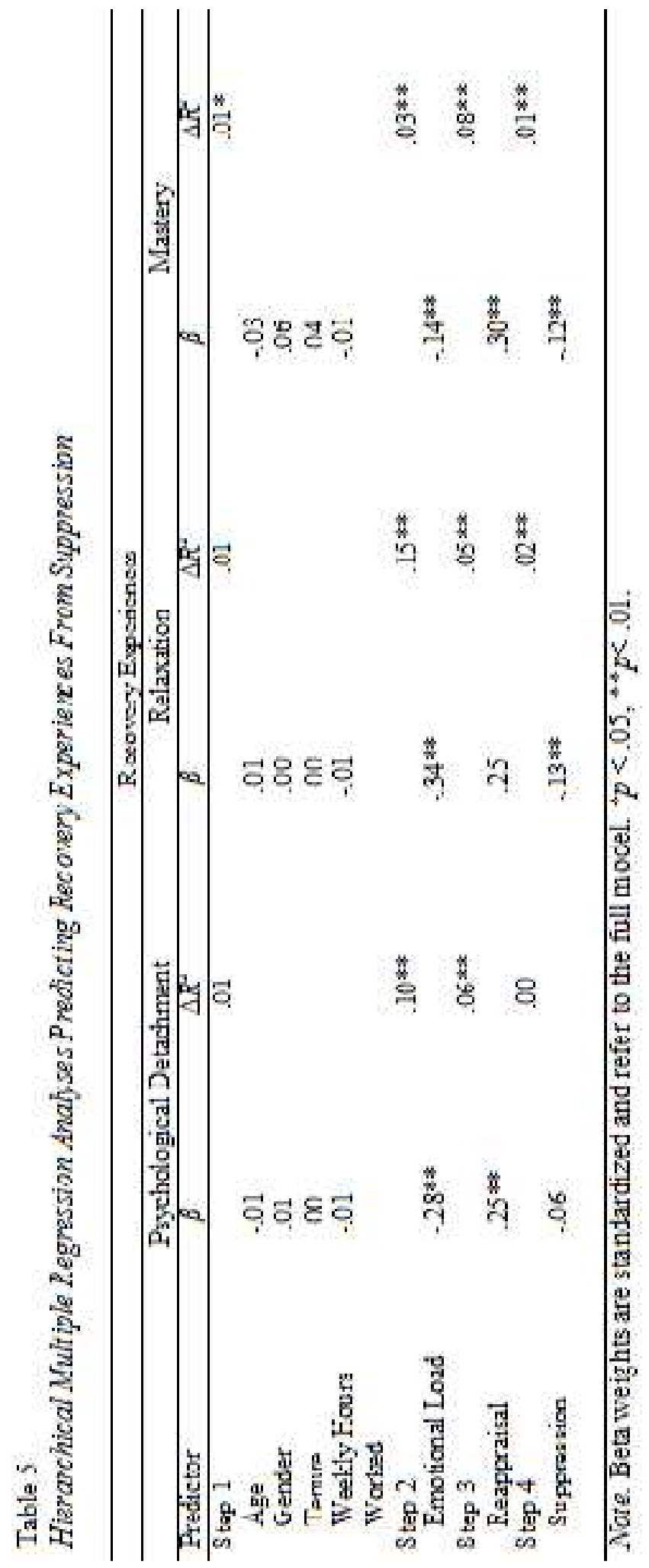




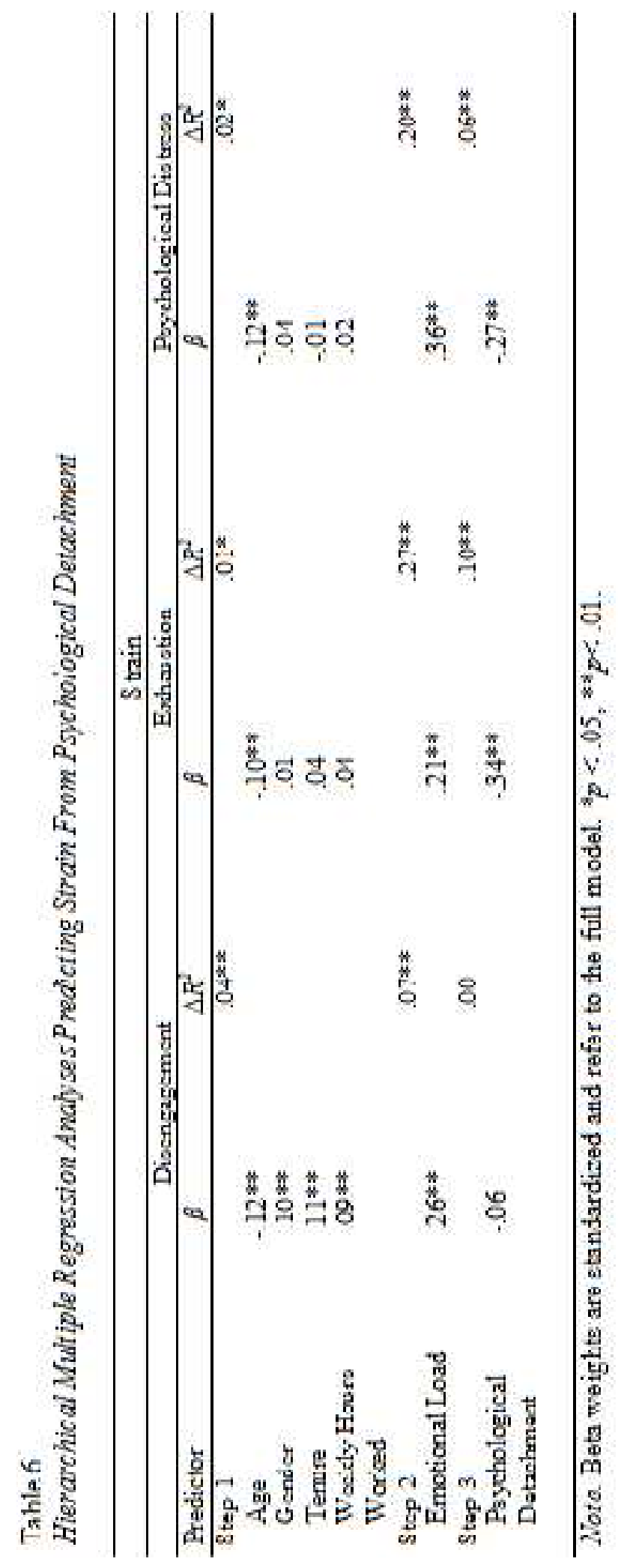




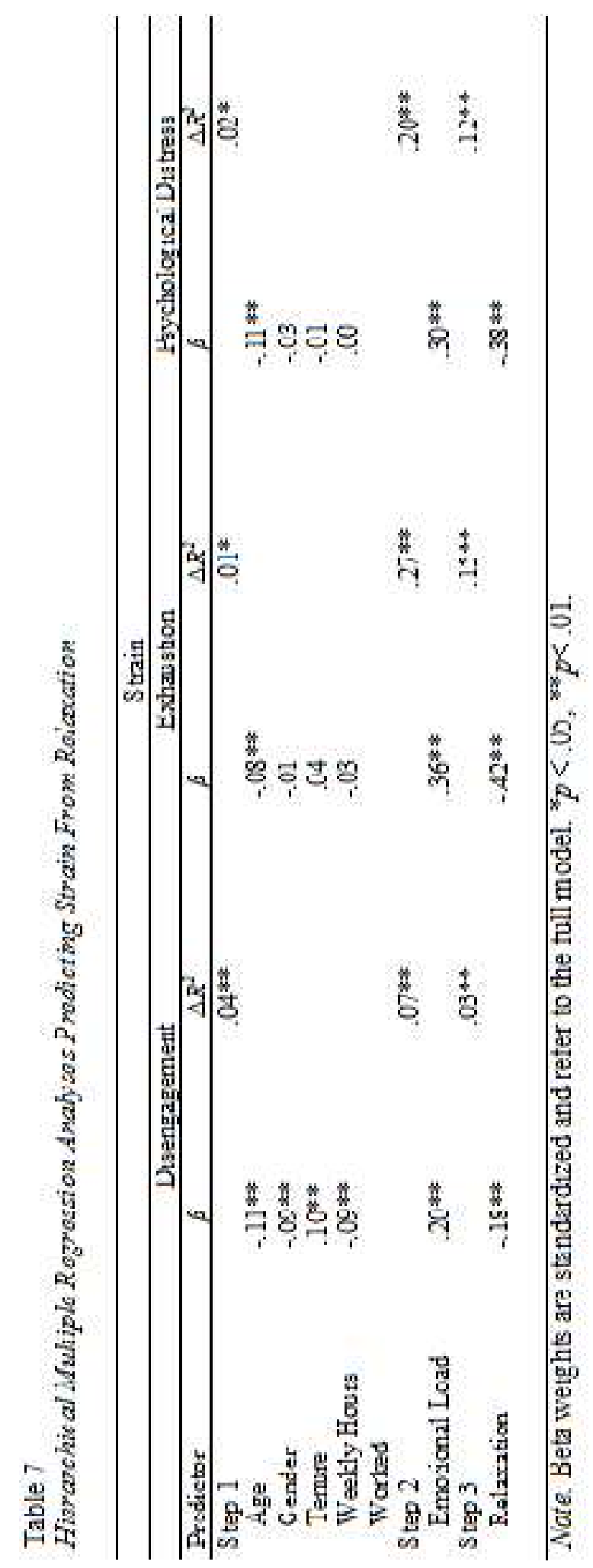




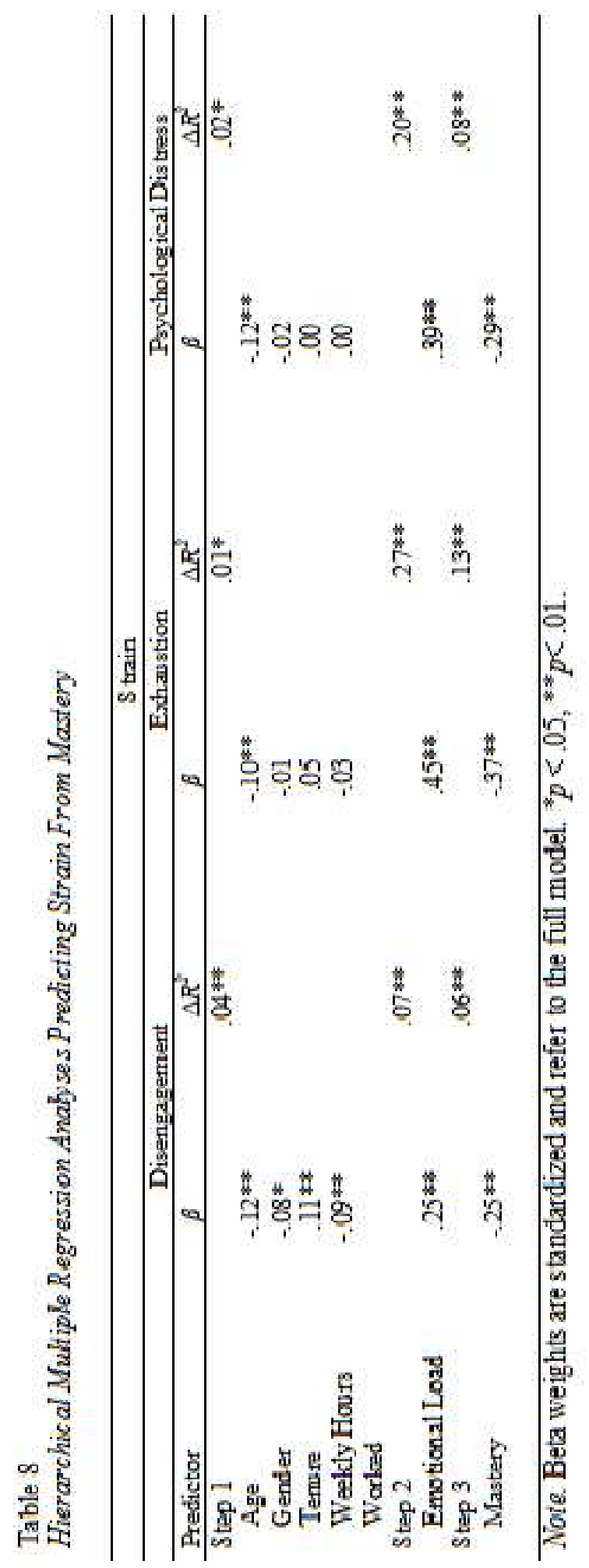




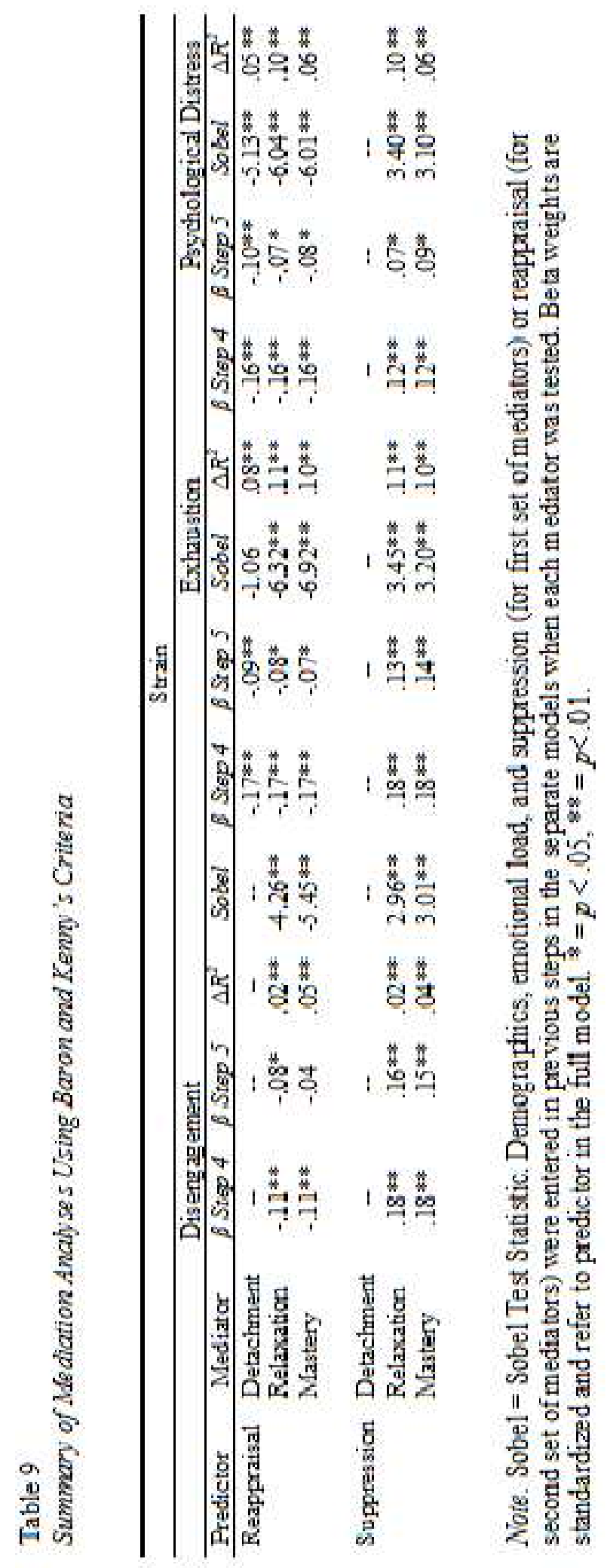



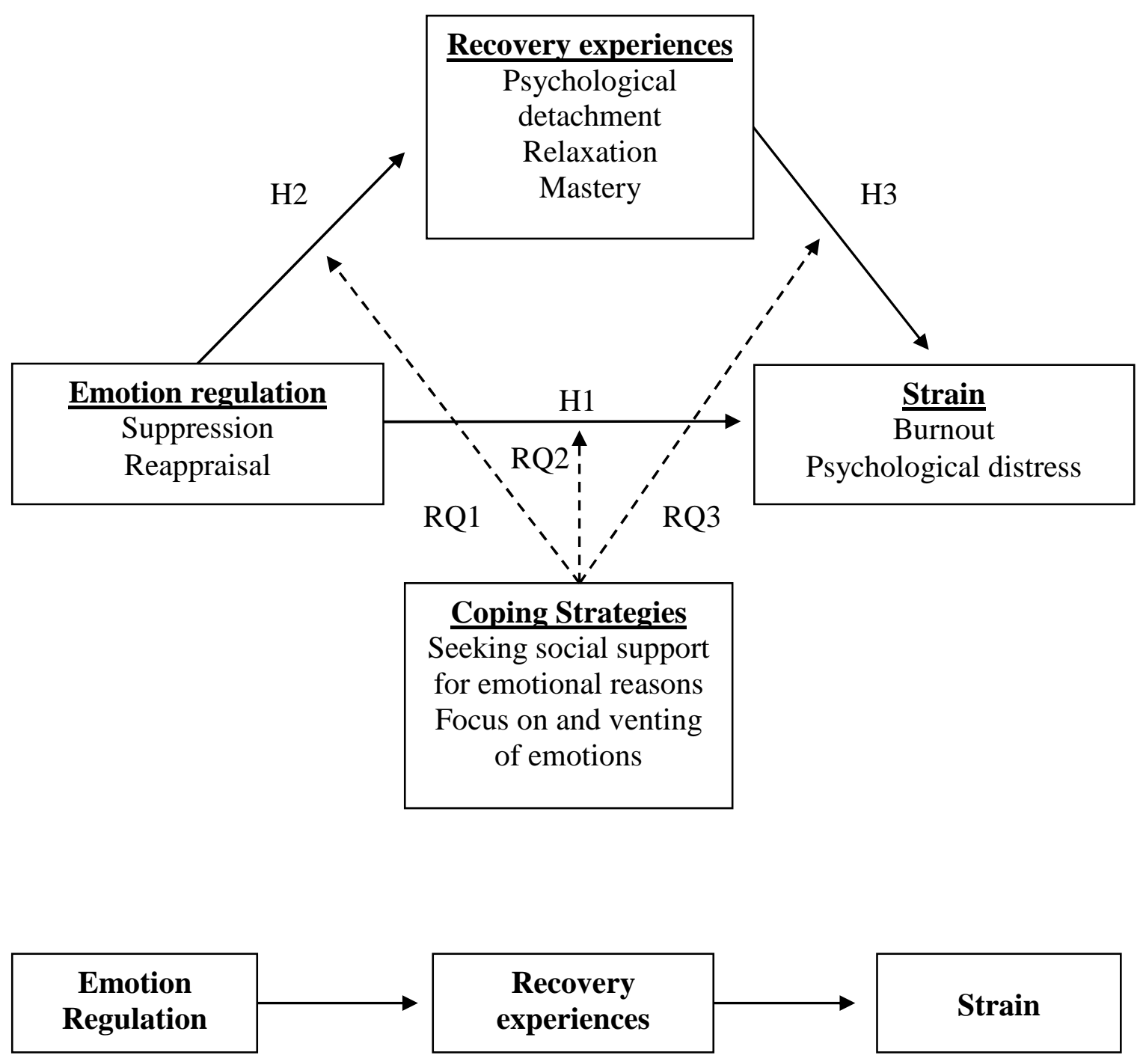

$\underline{\text { H4: Mediation }}$

Figure 1. Model of study variables. Solid lines denote hypothesized relationships. Dashed lines denote research questions. Hypothesis 3 was a replication of past literature. Hypothesis 1 was partially a replication of past literature. 


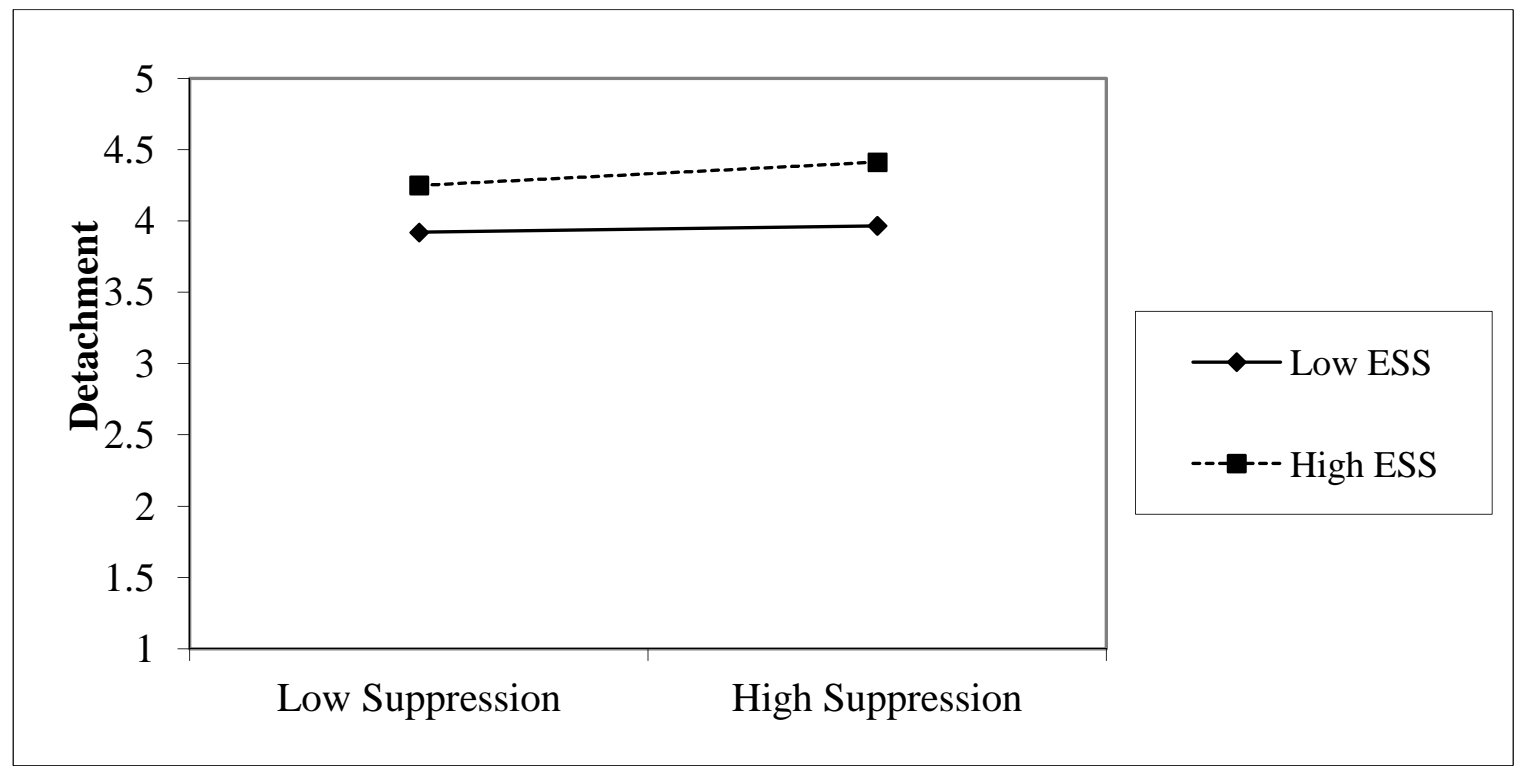

Figure 2. Interaction between suppression and emotional social support on detachment. 


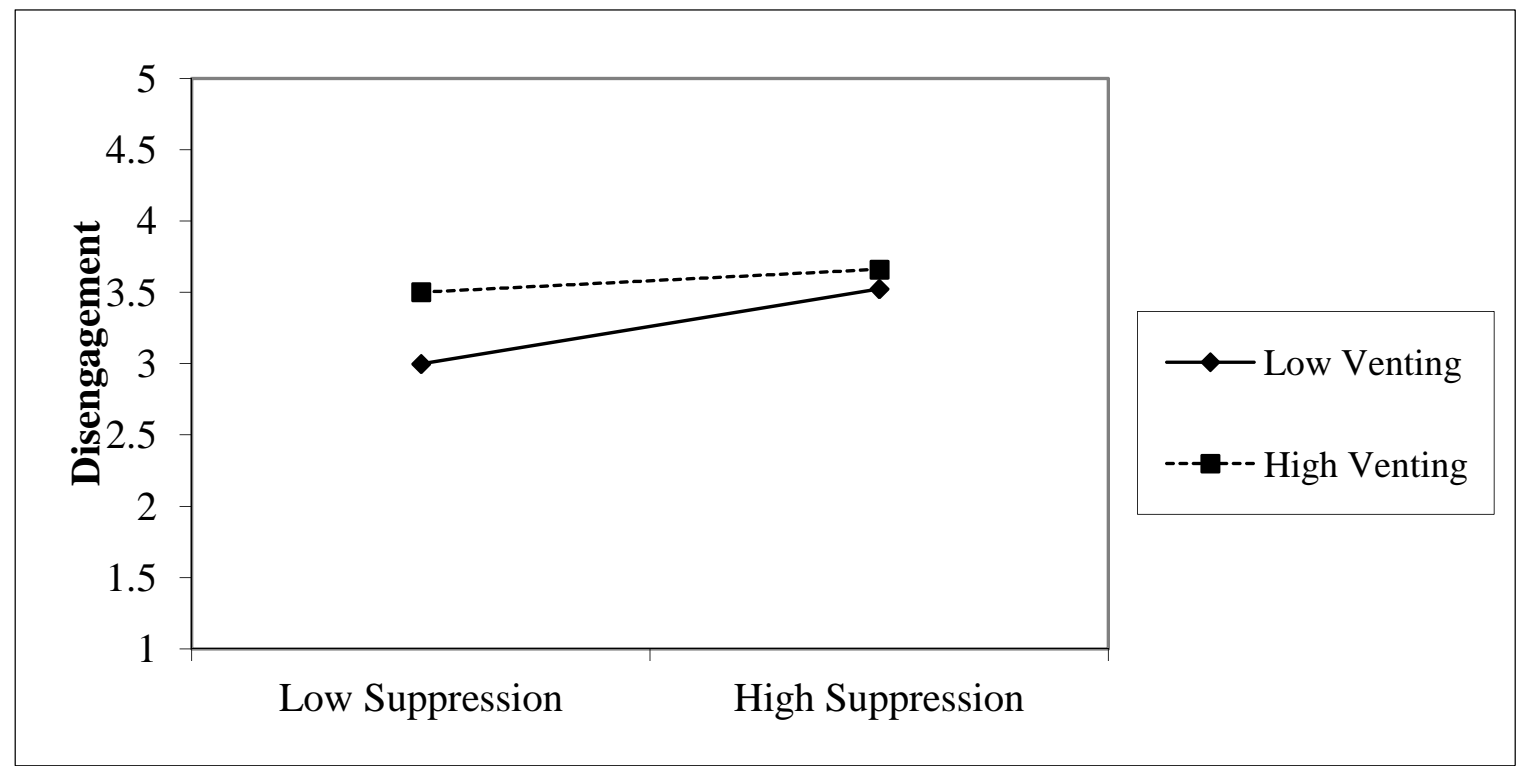

Figure 3. Interaction between suppression and venting on disengagement. 


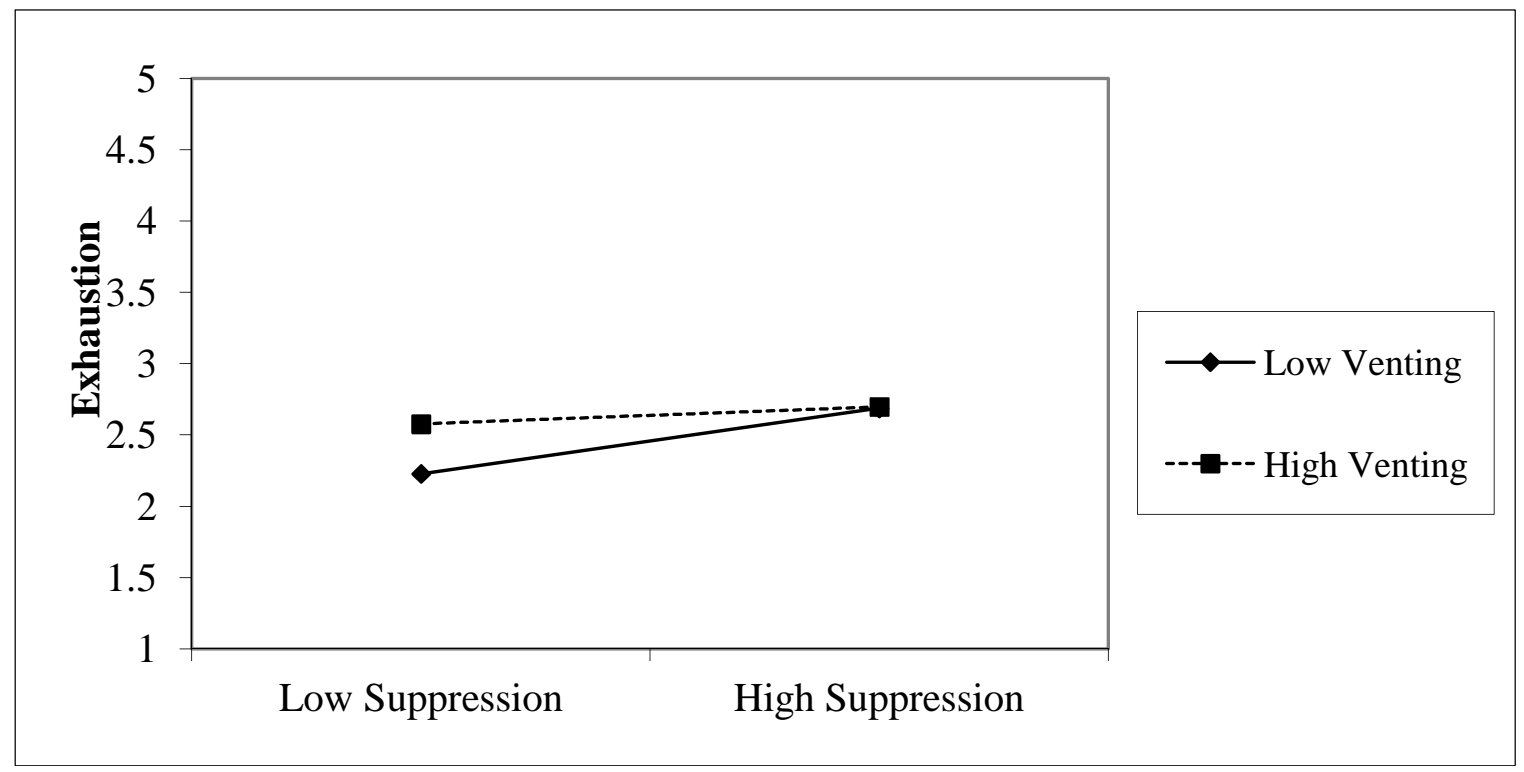

Figure 4. Interaction between suppression and venting on exhaustion. 


\section{References}

Allen, T.D., \& Kiburz, K.M. (2012). Trait mindfulness and work-family balance among working parents: The mediating effects of vitality and sleep quality. Journal of Vocational Behavior, 80, 372-379. doi: 10.1016/j.jvb.2011.09.002

Armstrong, G.S., \& Griffin, M.L. (2004). Does the job matter? Comparing correlates of stress among treatment and correctional staff in prisons. Journal of Criminal Justice, 32, 577-592. doi: 10.1016/j.jcrimjus.2004.08.007

Ashforth, B.E., \& Humphrey, R.H. (1993). Emotional labor in service roles: The influence of identity. Academy of Management Review, 18, 88-115. doi: 10.5465/AMR.1993.3997508

Baron, R.M., \& Kenny, D.A. (1986). The moderator-mediator variable distinction in social psychology research: Conceptual, strategic, and statistical considerations. Journal of Personality and Social Psychology, 51, 1173-1182. doi: 10.1037/00223514.51.6.1173

Baumeister, R.E., Bratslavsky, E., Muraven, M., \& Tice, D.M. (1998). Ego depletion: Is the active self a limited resource? Journal of Personality and Social Psychology, 74, 1252-1265. doi: 10.1037/0022-3514.74.5.1252

Beal, D. J., Trougakos, J. P., Weiss, H. M., \& Dalal, R. S. (2013, April 8). Affect Spin and the Emotion Regulation Process at Work. Journal of Applied Psychology. Advance online publication. doi: 10.1037/a0032559 
Bono, J.E., Foldes, H.J., Vinson, G., \& Muros, J.P. (2007). Workplace emotions: The role of supervision and leadership. Journal of Applied Psychology, 92, 1357-1367. doi: $10.1037 / 0021-9010.92 .5 .1357$

Brotheridge, C.M., \& Grandey, A.A. (2002). Emotional labor and burnout: Comparing two perspectives of "people work". Journal of Vocational Behavior, 60, 17-39. doi: $10.1006 /$ jvbe.2001.1815

Butler, E.A., Egloff, B., Wilhelm, F.H., Smith, N.C., Erickson, E.A., \& Gross, J.J. (2003). The social consequences of expressive suppression. Emotion, 3, 48-67. doi: $10.1037 / 1528-3542.3 .1 .48$

Carver, C.S., Scheier, M.F., \& Weintraub, J.K. (1989). Assessing coping strategies: A theoretically based approach. Journal of Personality and Social Psychology, 56, 267-283. doi: 10.1037/0022-3514.56.2.267

Côté, S. (2005). A social interaction model of the effects of emotion regulation on work strain. Academy of Management Review, 30, 509-530. doi:

10.5465/AMR.2005.17293692

Cropley, M., \& Purvis, L.M. (2003). Job strain and rumination about work issues during leisure time: A diary study. European Journal of Work and Organizational Psychology, 12, 195-207. doi: 10.1080/13594320344000093

Davidson, O.B., Eden, D., Westman, M., Cohen-Charash, Y., Hammer, L.B., \& Kluger, A.N. (2010). Sabbatical leave: Who gains and how much? Journal of Applied Psychology, 95, 953-964. doi: 10.1037/a0020068 
de Jonge, J., \& Dormann, C. (2006). Stressors, resources, and strain at work: A longitudinal test of the triple-match principle. Journal of Applied Psychology, 5, 1359-1374. doi: 10.1037/0021-9010.91.5.1359

de Ven, B.V., van den Tooren, M., \& Vlerick, P. (2013). Emotional job resources and emotional social support seeking as moderators of the relation between emotional job demands and emotional exhaustion: A two-wave panel study. Journal of Occupational Health Psychology, 18, 1-8. doi: 10.1037/a0030656

Demerouti, E., Bakker, A.B., Geurts, S., \& Taris, T. (2009). Daily recovery from workrelated effort during non-work time. In S. Sonnentag, P. L. Perrewe \& D. C. Ganster (Eds.), Current perspectives on job-stress recovery: Research in occupational stress and well being (Vol. 7, pp. 85-123). Bingley, UK: Emeral Group. doi: 10.1108/S1479-3555(2009)0000007006

Demerouti, E., Bakker, A.B., Nachreiner, F., \& Schaufeli, W.B. (2001). The job demands-resources model of burnout. Journal of Applied Psychology, 86, 499512. doi: 10.1303//0021-9010.86.3.499

Demerouti, E., Bakker, A.B., Vardakou, I., \& Kantas, A. (2003). The convergent validity of two burnout instruments: A multitrait-multimethod analysis. European Journal of Psychological Assessment, 18, 296-307. doi: 10.1027//1015-5759.19.1.12

Diefendorff, J.M., \& Greguras, G.J. (2009). Contextualizing emotional display rules: Examining the roles of targets and discrete emotions in shaping display rule perceptions. Journal of Management, 35, 880-898. doi:

$10.1177 / 0149206308321548$ 
Diefendorff, J.M., Richard, E.M., \& Yang, J. (2008). Linking emotion regulation strategies to affective events and negative emotions at work. Journal of Vocational Behavior, 73, 498-508. doi: 10.1016/j.jvb.2008.09.006

Dohrenwend, B.P., Shrout, P.E., Ergi, G.E., \& Mendelsohn, F.S. (1980). Measures of non-specific psychological distress and other dimensions of psychopathology in the general population. Archives of General Psychiatry, 37, 1229-1236. doi: $10.1017 / \mathrm{S} 0033291702006074$

Dollard, M.F., \& Winefield, A.H. (1998). A test of the demand-control/support model of work stress in correctional officers. Journal of Occupational Health Psychology, 3, 243-264. doi: 10.1037/1076-8998.3.3.243

Eby, L.T., \& Laschober, T.C. (2013, April). Rumination propensity and work-nonwork conflict: Can recovery experiences help? Paper presented at the 28th Annual Conference of the Society for Industrial and Organizational Psychology, Houston, TX.

Ekman, P., \& Friesen, W.V. (1975). Unmasking the face: A guide to recognizing emotions from facial clues. Englewood Cliffs, NJ: Prentice Hall.

Etzion, D. (2003). Annual vacation: Duration and relief from job stress and burnout. Anxiety, Stress and Coping: An International Journal, 16, 213-226. doi: $10.1080 / 10615806.2003 .10382974$

Etzion, D., Eden, D., \& Lapidot, Y. (1998). Relief from job stressors and burnout: Reserve service as a respite. Journal of Applied Psychology, 83, 377-585. doi: 10.1037/0021-9010.83.4.577 
Fritz, C., Lam, C.F., \& Spreitzer, G.M. (2011). It's the little things that matter: An examination of knowledge workers' energy management. Academy of Management Perspectives, 25, 28-39. doi: 10.5465/AMP.2011.63886528

Fritz, C., \& Sonnentag, S. (2005). Recovery, health, and job performance: Effects of weekend experiences. Journal of Occupational Health Psychology, 10, 187-199. doi: $10.1037 / 1076-8998.10 .3 .187$

Fritz, C., \& Sonnentag, S. (2006). Recovery, well-being, and performance-related outcomes: The role of workload and vacation experiences. Journal of Applied Psychology, 91, 936-945. doi: 10.1037/0021-9010.91.4.936

Fritz, C., Sonnentag, S., Spector, P.E., \& McInroe, J. (2010). The weekend matters: Relationships between stress recovery and affective experiences. Journal of Organizational Behavior, 31, 1137-1162. doi: 10.1002/job.672

Geurts, S.A.E., \& Sonnentag, S. (2006). Recovery as an explanatory mechanism in the relation between acute stress reactions and chronic health impairment. Scandinavian Journal of Work, Environment \& Health, 32, 482-492. doi: 10.5271/sjweh.1053

Goldberg, L.S., \& Grandey, A.A. (2007). Display rules versus display autonomy: Emotion regulation, emotional exhaustion, and task performance in a call center simulation. Journal of Occupational Health Psychology, 12, 301-318. doi: 10.1037/1076-8998.12.3.301 
Goldin, P.R., McRae, K., Ramel, W., \& Gross, J.J. (2008). The neural bases of emotion regulation: Reappraisal and suppression of negative emotion. Biological Psychiatry, 63, 577-586. doi: 10.1016/j.biopsych.2007.05.031

Grandey, A.A. (2000). Emotion regulation in the workplace: A new way to conceptualize emotional labor. Journal of Occupational Health Psychology, 5, 95-110. doi: 10.1037//1076-8998.5.1.95

Grandey, A.A., Foo, S.C., Groth, M., \& Goodwin, R.E. (2012). Free to be you and me: A climate of authenticity alleviates burnout from emotional labor. Journal of Occupational Health Psychology, 17, 1-14. doi: 10.1037/a0025102

Griffin, M.L., Hogan, N.L., Lambert, E.G., Tucker-Gail, K.A., \& Baker, D.N. (2010). Job involvement, job stress, job satisfaction, and organizational commitment and the burnout of correctional staff. Criminal Justice and Behavior, 37, 239-255. doi: $10.1177 / 0093854809351682$

Gross, J.J. (1998). The emerging field of emotion regulation: An integrative review. Review of General Psychology, 2, 271-299. doi: 10.1037/1089-2680.2.3.271

Gross, J.J. (2001). Emotion regulation in adulthood: Timing is everything. Current Directions in Psychological Science, 10, 214-219.

Gross, J.J., \& John, O.P. (2003). Individual differences in two emotion regulation processes: Implications for affect, relationships, and well-being. Journal of Personality and Social Psychology, 85, 348-362. doi: 10.1037/00223514.85 .2 .348 
Hagger, M.S., Wood, C., Stiff, C., \& Chatzisarantis, N.L.D. (2010). Ego depletion and the strength model of self-control: A meta-analysis. Psychological Bulletin, 136, 495-525. doi: 10.1037/a0019486

Hahn, V.C., Binnewies, C., Sonnentag, S., \& Mojza, E.J. (2011). Learning how to recover from job stress: Effects of a recovery training program on recovery, recovery-related self-efficacy, and well-being. Journal of Occupational Health Psychology, 16, 202-216. doi: 10.1037/a0022169

Hobfoll, S.E. (1989). Conservation of resources: A new attempt at conceptualizing stress. American Psychologist, 44, 513-524. doi: 10.1037/0003-066X.44.3.513

Hobfoll, S.E. (2002). Social and psychological resources and adaptation. Review of General Psychology, 6, 307-324. doi: 10.1037//1089-2680.6.4.307

Hochschild, A.R. (1983). The managed heart: Commercialization of human feelings. Berkeley: University of California Press.

Holman, D., Martinez-Inigo, D., \& Totterdell, P. (2009). Emotional labour, well-being, and performance. In C. L. Cooper \& S. Cartwright (Eds.), The Oxford handbook of organizational well-being. Oxford, U.K.: Oxford University Press.

$\mathrm{Hu} \square$ lsheger, U.R., Alberts, H.J.E.M., Feinholdt, A., \& Lang, J.W.B. (2013). Benefits of mindfulness at work: The role of mindfulness in emotion regulation, emotional exhaustion, and job satisfaction. Journal of Applied Psychology, 98, 310-325. doi: $10.1037 / \mathrm{a} 0031313$ 
Hülsheger, U.R., Lang, J.W.B., \& Maier, G.W. (2010). Emotional labor, strain, and performance: Testing reciprocal relationships in a longitudinal panel study. Journal of Occupational Health Psychology, 15, 505-521. doi: 10.1037/a0021003

Hülsheger, U.R., \& Schewe, A.F. (2011). On the costs and benefits of emotional labor: A meta-analysis of three decades of research. Journal of Occupational Health Psychology, 16, 361-389. doi: 10.1037/a0022876

Hunthausen, J.M., Truxillo, D.M., Bauer, T.N., \& Hammer, L.B. (2003). A field study of frame-of-reference effects on personality test validity. Journal of Applied Psychology, 88, 545-551. doi: 10.1037/0021-9010.88.3.545

Ilies, R., Dimotakis, N., \& Watson, D. (2010). Mood, blood pressure, and heart rate at work: an experience-sampling study. Journal of Occupational Health Psychology, 15, 120. doi: 10.1037/a0018350

John, O.P., \& Gross, J.J. (2004). Health and unhealthy emotion regulation: Personality processes, individual differences, and life span development. Journal of Personality, 72, 1301-1334. doi: 10.1111/j.1467-6494.2004.00298.x

Kessler, R.C., Andrews, L.J., Colpe, L.J., Hiripi, E., Mroczek, D.K., Normand, S.-L.T. (2002). Short screening scales to monitor population prevalences and trends in non-specific psychological distress. Psychological Medicine, 32, 959-976. doi: $10.1017 / \mathrm{S} 0033291702006074$

Kessler, R.C., \& Frank, R.G. (1997). The impact of psychiatric disorders on work loss days. Psychological Medicine, 27, 861-873. doi: 10.1017/S0033291797004807 
Kinnunen, U., Feldt, T., Siltaloppi, M., \& Sonnentag, S. (2011). Job demands-resources model in the context of recovery: Testing recovery experiences as mediators. European Journal of Work and Organizational Psychology, 20, 1-28. doi: $10.1080 / 1359432 X .2010 .524411$

Kivimäki, M., Leino-Arjas, P., Kaila-Kangas, L., Luukkonen, R., Vahtera, J., Elovainio, M. (2006). Is incomplete recovery from work a risk marker of cardiovascular death? Prospective evidence from industrial employees. Psychosomatic Medicine, 68, 402-407. doi: 10.1097/01.psy.0000221285.50314.d3

Kruml, S.M., \& Geddes, D. (2000). Catching fire without burning out: Is there an ideal way to perform emotional labor? In N. M. Ashkanasy, C. E. J. Härtel \& W. J. Zerbe (Eds.), Emotions in the workplace: Theory, research, and practice (pp. 177-188). Westport, CT: Quorum.

Kühnel, J., \& Sonnentag, S. (2011). How long do you benefit from vacation? A closer look at the fade-out of vacation effects. Journal of Organizational Behavior, 32 , 125-143. doi: 10.1002/job.699

Lambert, E.G., Hogan, N.L., Dial, K.C., Jiang, S., \& Khondaker, M.I. (2012). Is the job burning me out? An exploratory test of the job characteristics model on the emotional burnout of prison staff. The Prison Journal, 92, 3-23. doi: $10.1177 / 0032885511428794$

LaMontagne, A.D., D'Souza, R.M., \& Shann, C.B. (2012). Socio-demographic and work setting correlates of poor mental health in a population sample of working Victorians: Application in evidence-based intervention priority setting. 
International Journal of Mental Health Promotion, 14, 109-122. doi:

$10.1080 / 14623730.2012 .703048$

Lawrence, S.A., Troth, A.C., Jordan, P.J., \& Collins, A.L. (2011). A review of emotion regulation and development of a framework for emotion regulation in the workplace. Research in Occupational Stress and Well Being, 9, 197-263.

Lazarus, R.S. (1999). Stress and Emotion: A New Synthesis. New York: Springer Publishing Company.

Lazarus, R.S., \& Alfert, E. (1964). Short-circuiting of threat by experimentally altering cognitive appraisal. Journal of Abnormal and Social Psychology, 69, 195-205. doi: $10.1037 / \mathrm{h} 0044635$

Lazarus, R.S., \& Folkman, S. (1984). Stress, appraisal, and coping. New York: Springer.

Lee, R.T., \& Ashforth, B.E. (1996). A meta-analytic examination of the correlates of the three dimensions of job burnout. Journal of Applied Psychology, 81, 123-133. doi: 10.1037/0021-9010.81.2.123

Litman, J.A., \& Lunsford, G.D. (2009). Frequency of use and impact of coping strategies assessed by the COPE inventory and their relationships to post-event health and well-being. Journal of Health Psychology, 14, 982-991. doi:

$10.1177 / 1359105309341207$

Locke, E. A., \& Latham, G. P. (2006). New directions in goal-setting theory. Current Directions in Psychological Science, 15, 265-268. doi: 10.1111/j.14678721.2006.00449.x 
Marshall, N.L., Barnett, R.C., \& Sayer, A. (1997). The changing workforce, job stress, and psychological distress. Journal of Occupational Health Psychology, 2, 99107. doi: 10.1037?1076-8998.2.2.99

Marzuq, N., \& Drach-Zahavy, A.D. (2012). Recovery during a short period of respite: The interactive roles of mindfulness and respite experiences. Work \& Stress, 26, 175-194. doi: 10.1080/02678373.2012.683574

Maslach, C., Schaufeli, W.B., \& Leiter, M.P. (2001). Job burnout. Annual Review of Psychology, 52, 397- 422. doi: 10.1146/annurev.psych.52.1.397

Meijman, T.F., \& Mulder, G. (1998). Psychological aspects of workload. In P. J. D. Drenth, H. Thierry \& C. J. W. de (Eds.), Handbook of work and organizational psychology (Vol. 2, pp. 5-33). Hove, England: Psychology Press.

Melamed, S., Shirom, A., Toker, S., Berliner, S., \& Shapira, I. (2006). Burnout and risk of cardiovascular disease: Evidence, possible causal paths, and promising research directions. Psychological Bulletin, 132, 327-353. doi: 10.1037/00332909.132.3.327

Mikolajczak, M., Tran, V., Brotheridge, C.M., \& Gross, J.J. (2009). Using an emotion regulation framework to predict the outcomes of emotional labor. In N. M. Ashkanasy, W. J. Zerbe \& C. E. J. Hartel (Eds.), Research on emotion in organizations: Emotion in groups, organizations, and cultures (pp. 245-273). Bingley, UK: Emerald Group.

Moreno-Jiménez, B., Mayo, M., Sanz-Vergel, A.I., Geurts, S.A.E., Rodríguez-Muñoz, A., \& Garrosa, E. (2009). Effects of work-family conflict on employee's well- 
being: The moderating role of recovery experiences. Journal of Occupational Health Psychology, 14, 427-440. doi: 10.1037/a0016739

Morris, J.A., \& Feldman, D.C. (1996). The dimensions, antecedents, and consequences of emotional labor. Academy of Management Review, 21, 986-1010. doi:

10.5465/AMR.1996.9704071861

National Occupational Research Agenda (NORA), (2013). National public safety agenda: For occupational safety and health research and practice in the U.S. public safety sector.

Nylander, P.-Å., Lindberg, O., \& Bruhn, A. (2011). Emotional labour and emotional strain among Swedish prison officers. European Journal of Criminology, 8, 469483. doi: $10.1177 / 1477370811413806$

Obidoa, C., Reeves, D., Warren, N., Reisine, S., \& Cherniack, M. (2011). Depression and work family conflict among corrections officers. Journal of Occupational and Environmental Medicine, 53, 1294-1301. doi: 10.1097/JOM.0b013e3182307888

Podsakoff, P.M., MacKenzie, S.B., Lee, J.-Y., \& Podsakoff, N.P. (2003). Common method biases in behavioral research: A critical review of the literature and recommended remedies. Journal of Applied Psychology, 88, 879-903. doi: $10.1037 / 0021-9010.88 .5 .879$

Quick, J.C. (1999). Occupational health psychology: The convergence of health and clinical psychology with public health and preventative medicine in an organizational context. Journal of Occupational Health Psychology, 30, 123-128. doi: 10.1037/0735-7028.30.2.123 
Ragsdale, J.M., Beehr, T.A., Grebner, S., \& Han, K. (2011). An integrated model of weekday stress and weekend recovery of students. International Journal of Stress Management, 18, 153-180. doi: 10.1037/a0023190

Richards, J.M., \& Gross, J.J. (1999). Composure at any cost? The cognitive consequences of emotion suppression. Personality and Social Psychology Bulletin, 25, 10331044. doi: 10.1177/01461672992511010

Rutter, D.R., \& Fielding, P.J. (1988). Sources of occupational stress: An examination of British prison officers. Work \& Stress: An International Journal of Work, Health \& Organisations, 2, 291-299. doi: 10.1080/02678378808257490

Schaufeli, W.B., \& Peeters, M.C.W. (2000). Job stress and burnout among correctional officers: A literature review. International Journal of Stress Management, 7, 1948. doi: 10.1023/A:1009514731657

Shaffer, J.A., \& Postlethwaite, B.E. (2012). A matter of context: A meta-analytic investigation of the relative validity of contextualized and noncontextualized personality measures. Personnel Psychology, 65, 445-494. doi: 10.1111/j.1744$6570.2012 .01250 . x$

Sheldon, K.M., Ryan, R.M., Rawsthorne, L.J., \& Ilardi, B. (1997). Trait self and true self: Cross-role variation in the Big-Five personality traits and its relations with psychological authenticity and subjective well-being. Journal of Personality and Social Psychology, 73, 1380-1393. doi: 10.1037/0022-3514.73.6.1380 
Shirom, A. (2003). Job-related burnout: A Review. In J. C. Quick \& L. E. Tetrick (Eds.), Handbook of occupational health psychology (pp. 245-264). Washington, DC, US: American Psychological Association. doi: 10.1037/10474-012

Siltaloppi, M., Kinnunen, U., \& Feldt, T. (2009). Recovery experiences as moderators between psychosocial work characteristics and occupational well-being. Work \& Stress, 23, 330-348. doi: 10.1080/02678370903415572

Sobel, M.E. (1982). Asymptotic confidence intervals for indirect effects in structural equation models. In S. Leinhardt (Ed.), Sociological methodology (pp. 290-321). Washington, D. C.: Sociological Association. doi: 10.2307/270723

Sonnentag, S., \& Bayer, U. (2005). Switching off mentally: Predictors and consequences of psychological detachment from work during off-job time. Journal of Occupational Health Psychology, 10, 393-414. doi: 10.1037/1076-8998.10.4.393

Sonnentag, S., Binnewies, C., \& Mojza, E.J. (2008). "Did you have a nice evening?" A day-level study on recovery experiences, sleep and work-relevant affect. Journal of Applied Psychology, 93, 674-684.

Sonnentag, S., \& Fritz, C. (2007). The recovery experience questionnaire: Development and validation of a measure for assessing recuperation and unwinding from work. Journal of Occupational Health Psychology, 12, 204-221. doi: 10.1037/10768998.12.3.204

Sonnentag, S., \& Grant, A.M. (2012). Doing good at work feels good at home, but not right away: When and why perceived prosocial impact predicts positive affect. Personnel Psychology, 65, 495-530. doi: 10.1111/j.1744-6570.2012.01251.x 
Sonnentag, S., Kuttler, I., \& Fritz, C. (2010). Job stressors, emotional exhaustion, and need for recovery: A multi-source study on the benefits of psychological detachment. Journal of Vocational Behavior, 76, 355-365. doi: 10.1016/j.jvb.2009.06.005

Spector, P.E., Zapf, D., Chen, P.Y., \& Frese, M. (2000). Why negative affectivity should not be controlled in job stress research: Don't throw out the baby with the bath water. Journal of Organizational Behavior, 21, 79-95. doi: 10.1002/(SICI)10991379(200002)21:1<79::AID-JOB964>3.0.CO;2-G

Spinaris, C., \& Denhof, M. (2011). Post-traumatic stress disorder in the correction ranks: Oregon analysis: Desert Waters Correctional Outreach.

Stack, S.J., \& Tsoudis, O. (1997). Suicide risk among correctional officers: A logistic regression analysis. Archives of Suicide Research, 3, 183-186. doi: $10.1080 / 13811119708258270$

Stanton, A.L., \& Low, C.A. (2012). Expressing emotions in stressful contexts: Benefits, moderators, and mechanisms. Current Directions in Psychological Science, 21, 124-128. doi: 10.1177/0963721411434978

Stone, A.A., Kennedy-Moore, E., \& Neale, J.M. (1995). Association between daily coping and end-of-day mood. Health Psychology, 14, 341-349.

Tabachnick, B.G., \& Fidell, L.S. (2007). Using multivariate statistics (5th ed.). Boston: Pearson / Allyn and Bacon.

Thiel, C., Connelly, S., \& Griffith, J. (2013, April). When bossy is better: Leaderfacilitated emotional management and empathy. Paper presented at the 28th 
Annual Conference of the Society for Industrial and Organizational Psychology, Houston, TX.

van Veldhoven, M., \& Meijman, T. (1994). Het meten van psychosociale arbeidsbelasting met een vragenlijst. Amsterdam: Nederlands Instituut voor Arbeidsomstandigheden.

Viswesvaran, C., Sanchez, J.I., \& Fisher, J. (1999). The role of social support in the process of work stress: A meta-analysis. Journal of Vocational Behavior, 54, 314334. doi: 10.1006/jvbe.1998.1661

Volmer, J., Binnewies, C., Sonnentag, S., \& Niessen, C. (2012). Do social conflicts with customers at work encroach upon our private lives? A diary study. Journal of Occupational Health Psychology, 17, 304-315. doi: 10.1037/a0028454

Watkins, E.R. (2008). Constructive and unconstructive repetitive thought. Psychological Bulletin, 134, 163-206. doi: http://dx.doi.org/10.1037\%2F0033-2909.134.2.163

Wolever, R.Q., Bobinet, K.J., McCabe, K., Mackenzie, E.R., Fekete, E., \& Kusnick, C.A. (2012). Effective and viable mind-body stress reduction in the workplace: A randomized control trial. Journal of Occupational Health Psychology, 17, 246258. doi: $10.1037 / \mathrm{a} 0027278$

Wood, R.E., Goodman, J.S., Beckmann, N., \& Cook, A. (2008). Mediation testing in management research: A review and proposals. Organizational Research Methods, 11, 270-295. doi: 10.1177/1094428106297811

Wright, T.A., Cropanzano, R., Bonett, D.G., \& Diamond, W.J. (2009). The role of employee psychological well-being in cardiovascular health: When the twain 
shall meet. Journal of Organizational Behavior, 30, 193-208. doi:

\subsection{2/job.592}

Zohar, D. (1997). Predicting burnout with a hassle-based measure of role demands. Journal of Organizational Behavior, 18, 101-115. doi: 10.1002/(SICI)10991379(199703)18:2<101::AID-JOB788>3.0.CO;2-Y 


\author{
Appendix A \\ Survey Items \\ All Scales Self-Reports
}

\title{
Emotion Regulation
}

Instructions: The following statements ask you how you experienced and expressed your emotions WHILE AT WORK, during the past 30 days. Please indicate to what extent you agree with each statement.

1. When I wanted to feel more positive emotion (such as joy or amusement), I changed what I was thinking about.

2. I kept my emotions to myself.

3. When I wanted to feel less negative emotion (such as sadness or anger), I changed what I was thinking about.

4. When I was feeling positive emotions, I was careful not to express them.

5. When I was faced with a stressful situation, I made myself think about it in a way that helped me stay calm.

6. I controlled my emotions by not expressing them.

7. When I wanted to feel more positive emotion, I changed the way I was thinking about the situation.

8. I controlled my emotions by changing the way I was thinking about the situation I was in.

9. When I was feeling negative emotions, I made sure not to express them.

10. When I wanted to feel less negative emotion, I changed the way I was thinking about the situation.

Response options: $(1=$ Not At All to $5=$ Very Much $)$

Reappraisal Items: 1, 3, 5, 7, 8, 10; Suppression Items: 2, 4, 6, 9.

\section{Strain}

Instructions: To what extent do you agree with the following statements? In the past month...

Disengagement:

1. I always found new and interesting aspects in my work. (R)

2. It happened more and more often that I talked about my work in a derogatory way.

3. I tended to think less during my work and just execute it mechanically.

4. I experienced my work as a real challenge. $(\mathrm{R})$ 
5. Over time, one loses the internal relationship with one's work.

6. Sometimes I felt really sick about my work tasks.

7. I could not imagine another occupation for myself. (R)

8. I got more and more engaged in my work. (R)

Emotional Exhaustion:

1. There were days that I felt already tired before I went to work.

2. After my work, I needed more time to relax than in the past to become fit again.

3. I could stand the pressure of my work very well. (R)

4. During my work, I often felt emotionally drained.

5. After my work, I usually felt still totally fit for my leisure activities. (R)

6. After my work, I usually felt worn out and weary.

7. When I worked, I usually felt vital. (R)

8. I could manage the amount of work well. (R)

Response options: $(1=$ Not At All to $5=$ Very Much $)$

Psychological Distress:

1. In the past month, how often have you felt so sad nothing could cheer you up?

2. In the past month, how often have you felt nervous?

3. In the past month, how often have you felt restless or fidgety?

4. In the past month, how often have you felt hopeless?

5. In the past month, how often have you felt that everything was an effort?

6. In the past month, how often have you felt worthless?

Response options: $(1=$ None of the Time, $2=$ A Little of the Time, $3=$ Some of the Time, $4=$ Most of the Time, $5=$ All of the Time)

\section{Recovery Experiences}

Instructions: To what extent do you agree with the following statements? OUTSIDE OF WORK, in the past month...

Psychological Detachment:

1. I forgot about work.

2. I didn't think about work at all.

3. I distanced myself from work.

4. I got a break from the demands of work.

Relaxation:

1. I kicked back and relaxed.

2. I did things that were relaxing.

3. I used the time to relax.

4. I took time for leisure. 
Mastery:

1. I learned new things.

2. I sought out mental challenges.

3. I did things that challenged me.

4. I did something to broaden my horizons.

Response options: $(1=$ Not At All to $5=$ Very Much $)$

\section{Coping Strategies}

Instructions: The following questions ask you to indicate what you generally do and feel, when you experience stressful events. Obviously, different events bring out somewhat different responses, but think about what you usually do when you are under a lot of stress.

When I am under stress...

Seeking Support for Emotional Reasons:

1. I discuss my feelings with someone.

2. I try to get emotional support from friends or relatives.

3. I get sympathy and understanding from someone.

4. I talk to someone about how I feel.

Focus On and Venting of Emotions:

1. I get upset and let my emotions out.

2. I get upset, and am really aware of it.

3. I let my feelings out.

4. I feel a lot of emotional distress and I find myself expressing those feelings a lot.

Response options: $(1=$ Never, $2=$ Rarely, $3=$ Sometimes, $4=$ Usually, $5=$ Often $)$

\section{Control Variables}

Emotional Load

Instructions: Consider the past month when answering the following questions.

1. Did your work demand a lot from you emotionally?

2. Were you confronted with things that affected you emotionally in your work?

3. Did your work put you in emotionally upsetting situations?

Response options: $(1=$ Very rarely or never, $2=$ Rarely (once a week), $3=$ Sometimes (once a day), 4 = Often (several times a day), 5 = Several times an hour) 
Negative Affect

Instructions: To what extent do you experience the following moods in general?

1. Scared

2. Afraid

3. Upset

4. Distressed

5. Jittery

6. Nervous

7. Ashamed

8. Guilty

9. Irritable

10. Hostile

Response options: $(1=$ Never, $2=$ Rarely, $3=$ Sometimes, $4=$ Usually, $5=$ Often $)$ 
Appendix B

\section{Sample email from Mike VanPatten, AOCE Leadership:}

Everyone,

We have been working on and supporting the PSU / DOC survey that will help to examine the work stress, possible imbalances and wellness that our minds and bodies go through. The survey data collected is confidential and will be utilized to improve our over occupational health and work environment.

By volunteering to participate in the survey is your chance to honestly document the demands and effects on your physical and mental wellbeing at work and at home. There are critical situations and sometimes even the inmate culture itself that can leave long lasting traumatic, emotional, and physical health effects on us and then transition to our family life. Watching the backs of your fellow staff is not just for the physical assault anymore, it also should incorporate the verbal, mental, and traumatic aspect of our careers as Correctional Professionals, this is the first step in calibrating for the future.

If you should have any questions please feel free to contact me also by e-mail or on my cell 503-507-6992.

Be safe and support each other

Sgt. Michael Van Patten, Special Operations Sergeant Oregon State Penitentiary (503) 378-4063

AOCE President 
Appendix C

\section{Sample email from Tim Woolery AFSCME Leadership:}

Correctional Professionals at X \& X,

I realize that you have seen a couple communications that have been sent to you regarding the Portland State University Correctional Officer Stress and Well-being study (included below). But I felt the obligation to encourage those of you who have not yet participated to do so at this time.

As Mr. Gower outlined, this is an independent study that is NOT related to PEBB or HEM or several other studies that may have been conducted recently. This is a research project that is genuinely designed and for the sole purpose of gathering information that will lead to a better understanding of your issues and concerns both on and off the job. It is my hope that will create data and justifications that will lead to making improvements in working conditions for people in this challenging career field as well as off duty life. The survey is anonymous and only the aggregate data will be published or shared once complete.

If there are any operational roadblocks to being able to complete the survey, please contact your Superintendent in order to see if there is a way to help facilitate as many people participating as possible.

ONLINE SURVEY:

https://portlandstate.qualtrics.com//SE/?SID=SV_1QRwxtE0KyNobWI

Tim Woolery

Staff Representative

Oregon AFSCME Council 75

Salem Office

1400 Tandem Avenue NE

Salem, Oregon 97301

Office 503-370-2522 Ext 232 or 800-521-5954

Fax 503-370-7725 


\begin{abstract}
Appendix D
Survey Recruitment Email From Assistant Director of Operations

$<$ Date $>$
\end{abstract}

To: $\mathrm{X}$ and X Security Staff

From: Michael Gower, Assistant Director of Operations

RE: Portland State University Correctional Officer Stress and Well-being Survey

Without a doubt, correctional officers in Oregon work very hard to maintain the security of our institutions and to ensure the safety of both inmates and coworkers. Unfortunately, our work can be very stressful and sometimes that stress spills over into our personal lives. The demands of our profession can create an imbalance between our work and home lives, and that imbalance can sometimes have negative effects on our overall happiness and wellbeing.

ODOC wants to combat these negative effects and help staff feel better in their jobs and at home. In order to do that, we are partnering with researchers at Portland State University (PSU) on a survey to help us examine work stress and work-life balance in correctional staff. Responses to this survey will help us improve the work environment of correctional staff.

There are a few things you should know about the survey:

$\circ$ The survey is anonymous. The survey is voluntary, but we hope that all security staff will participate. The more staff participate, the better picture we will have of work stress and work-life balance among Oregon correctional officers.

o The data obtained from the survey will only be used for research purposes and to inform the development of recommendations to improve correctional officers' work environment.

O The survey is NOT associated with PEBB's Health Engagement Model (HEM).

O The survey is not associated with Desert Waters Correctional Outreach (DWCO).

O The survey is also not associated with the OHSU Health Promotion and Protection Study that is ongoing at a few institutions.

Both AFSCME and AOCE are in full support of this project. ODOC's Research \& Evaluation unit and the group of researchers from PSU have been working closely with representatives from both labor organizations since the start of the project.

The survey will go out to security staff at ALL institutions, two-three facilities at a time (in no particular order). 
O Although it may seem lengthy, the survey only takes about 25 minutes to complete.

Please consider participating in this important survey. You can complete the survey on paper or online using the link below. Paper copies of the survey, along with stamped envelopes to return completed surveys to the researchers at PSU, are available at your institution. Please watch your email for a message from your institution leadership about where you can pick up a paper copy of the survey.

\section{ONLINE SURVEY:}

https://portlandstate.qualtrics.com//SE/?SID=SV_1QRwxtE0KyNobWI

If you have questions about the survey, you may contact the principal investigator at PSU, Dr. Charlotte Fritz, at fritzc@ pdx.edu or (503) 725-3980. You may also contact Margaret Braun in the ODOC Research \& Evaluation Unit at margaret.j.braun@doc.state.or.us or (503) 945-9001.

Take care,

Michael F. Gower-Assistant Director

Operations Division

2575 Center St.

Salem, OR. 97301

Office (503) 945-7144 
Appendix E

\section{PSU Occupational Health Survey Email Template For Superintendents}

\section{OPTION 1:}

It is clear, the work you do in corrections has an impact on the overall public safety of our communities. Through national studies it is also clear that corrections work is stressful and impacts all of us in many ways, unfortunately these impacts are often manifested in subtle ways while other times in not so subtle ways. Regardless of how stress presents itself it takes its toll on our health, our personal lives, and our families. To better understand the impacts and help address this issue the department has teamed up with Portland State University to gain a better understanding of how Oregon corrections work impacts our Oregon corrections professionals, starting with those in the security series.

$<$ INSERT STAFF MEMBERS' NAMES HERE> are leading the effort at $<$ INSTITUTION $>$ to help PSU hear from each of you individually regarding how your job impacts your life through a confidential survey that you can complete either electronically or on paper. Taking the survey is voluntary but I encourage each of you to anonymously and confidentially voice how corrections work has and is impacting your life. We can collectively better understand and address the needs of our corrections professionals if we have information germane to Oregon rather than a national perspective.

I hope you all will join in the department's effort to better understand and deal with the impacts of Oregon corrections work on you and your coworkers.

If you would rather do the survey on paper instead of electronically please get with $<$ INSERT STAFF MEMBERS' NAMES>. If you have any questions or concerns feel free to contact <INSERT STAFF MEMBERS' NAMES>, or myself.

\section{OPTION 2:}

As you can see from the email below, Portland State is going to conduct a survey to examine work stress and work life balance for correctional series staff. At this time the survey has been targeted at the correctional series at the institutions. This survey is an excellent opportunity for all of us to understand potential difficulties in our work situation and how they may be affecting our personal lives. As stated it is anonymous. I highly encourage all staff to participate, the information collected will help both staff presently working and those that will come after us. It is not often that researchers have made themselves available to collect data on correctional officers, it is a stressful job and 
we are largely ignored as public safety officers. I hope you will all engage and complete the survey; any information collected that can affect us positively should be embraced.

If you are not comfortable with completing the survey on line please contact <INSERT STAFF MEMBERS' NAMES> and they will work with you to get you a hard copy and envelope. <INSERT STAFF MEMBERS' NAMES> will also have paper copies available at briefings.

The survey will take a bit of your time, I encourage you to work with the OIC if you require uninterrupted time to complete it.

If you have any questions or concerns please to not hesitate to contact me or any of the contacts listed below.

Thank you all in advance for your participation. 
Appendix F

First reminder email (Send one week after initial email from Central Office)

Dear X and X Security staff,

We have had a great response to the PSU Correctional Officer Stress and Well-being Survey so far. Thank you so much to everyone who has already participated. The more people who respond, the better equipped our agency will be to make changes that will improve the overall health and well-being of our valued staff.

If you have not had time to complete a survey but would like to participate, there is still time. The deadline for online or paper completion of the survey for security staff at $X$ and $\mathrm{X}$ is $\langle$ Date $\rangle$. Please complete the survey one time only, either online or on paper, by

$<$ Date $>$.

ONLINE SURVEY:

https://portlandstate.qualtrics.com//SE/?SID=SV_1QRwxtE0KyNobWI

As always, if you have questions about the survey you may contact the principal investigator at PSU, Dr. Charlotte Fritz, at fritzc@ pdx.edu or (503) 725-3980. You may also contact me directly in the ODOC Research \& Evaluation Unit at margaret.j.braun@doc.state.or.us or (503) 945-9001.

Take care and be well!

Margaret J. F. Braun, PhD

Research Analyst

Oregon Dept. of Corrections

2575 Center St. NE

Salem, OR. 97301

503.945.9001 


\section{Appendix G}

\section{Second reminder email (Send two weeks after initial email from Central Office)}

Hello again $X$ and $X$ Security staff,

If you have not yet had time to participate in the PSU Correctional Officer Stress and Well-being survey, I am happy to inform you that the deadline has been extended to next <Day, Date>. If you would like to take the survey, please click on the link below or approach the designated staff member(s) in your institution for a paper copy and pre-paid envelope. Each and every person's responses are extremely valuable. The more people respond, the better/more solid answers PSU researchers will have to the questions they ask and the better we can make plans for changes in the future that may help reduce work stress and increase work-life balance.

\section{If you have not yet filled out a survey, please click here:} https://portlandstate.qualtrics.com//SE/?SID=SV_1QRwxtE0KyNobWI

Thank you very much to those of you who have already participated! We greatly appreciate you taking the time to respond.

If you have questions you may contact the principal investigator at PSU, Dr. Charlotte Fritz, at fritzc@ pdx.edu or (503) 725-3980. You may also contact Margaret Braun in the ODOC Research \& Evaluation Unit at margaret.j.braun@ doc.state.or.us or (503) 9459001.

Margaret J. F. Braun, PhD

Research Analyst

Oregon Dept. of Corrections

2575 Center St. NE

Salem, OR. 97301

503.945.9001 


\section{Appendix $\mathrm{H}$}

\section{Research Collaboration - ODOC- Portland State University Memo of Agreement}

\section{$12 / 1 / 11$}

The understanding is that researchers at Portland State University (L. Hammer, C. Fritz, and 2 graduate students) will collaborate on a project to better understand the relationships between correctional staff work stress, work-family conflict, well-being and self-destructive behaviors.

Specifically, PSU researchers will develop a baseline survey based on their knowledge of Occupational Health Psychology, site visits to several prisons, and interviews with several Co's. Surveys will be distributed among ODOC correctional officers (Cos). ODOC will be responsible for the administration of the survey.

The plan is to administer the survey in March 2012.

PSU researchers will have full access to the data collected through the baseline survey to conduct their own research (including two thesis projects).

Based on the collected data, PSU researchers together with members from the ODOC will work out recommendations as well next steps for research collaboration.

Any work outside of the scope of this Memo of Agreement will need to be discussed and will be at an additional cost. 
Appendix I

Corrections Officer and Inmate Population by Facility (as of March 25, 2013)

\begin{tabular}{lcccc}
\multicolumn{1}{c}{ Facility } & $\#$ & $\begin{array}{c}\text { Inmate } \\
\text { Population }\end{array}$ & $\begin{array}{c}\text { Corrections } \\
\text { Officers }\end{array}$ & $\begin{array}{c}\text { Inmate: CO } \\
\text { Ratio }\end{array}$ \\
\hline Columbia River Correctional Institution & 1 & 568 & 68 & $8.35: 1$ \\
South Fork Forest Camp & 2 & 188 & 17 & $11.06: 1$ \\
Coffee Creek Correctional Facility & 3 & 1507 & 286 & $5.27: 1$ \\
Santiam Correctional Institution & 4 & 421 & 54 & $7.80: 1$ \\
Deer Ridge Correctional Institution & 5 & 748 & 194 & $3.86: 1$ \\
Eastern Oregon Correctional Institution & 6 & 1642 & 243 & $6.76: 1$ \\
Mill Creek Correctional Facility & 7 & 287 & 39 & $7.36: 1$ \\
Oregon State Correctional Institution & 8 & 861 & 99 & $8.70: 1$ \\
Oregon State Penitentiary & 9 & 2034 & 269 & $7.56: 1$ \\
Powder River Correctional Facility & 10 & 266 & 38 & $7.00: 1$ \\
Shutter Creek Correctional Institution & 11 & 260 & 44 & $5.91: 1$ \\
Snake River Correctional Institution & 12 & 3075 & 552 & $5.57: 1$ \\
Warner Creek Correctional Facility & 13 & 389 & 54 & $7.20: 1$ \\
Two Rivers Correctional Institution & 14 & 1719 & 280 & $6.14: 1$ \\
\hline Total & & 13965 & 2237 & $6.24: 1$
\end{tabular}




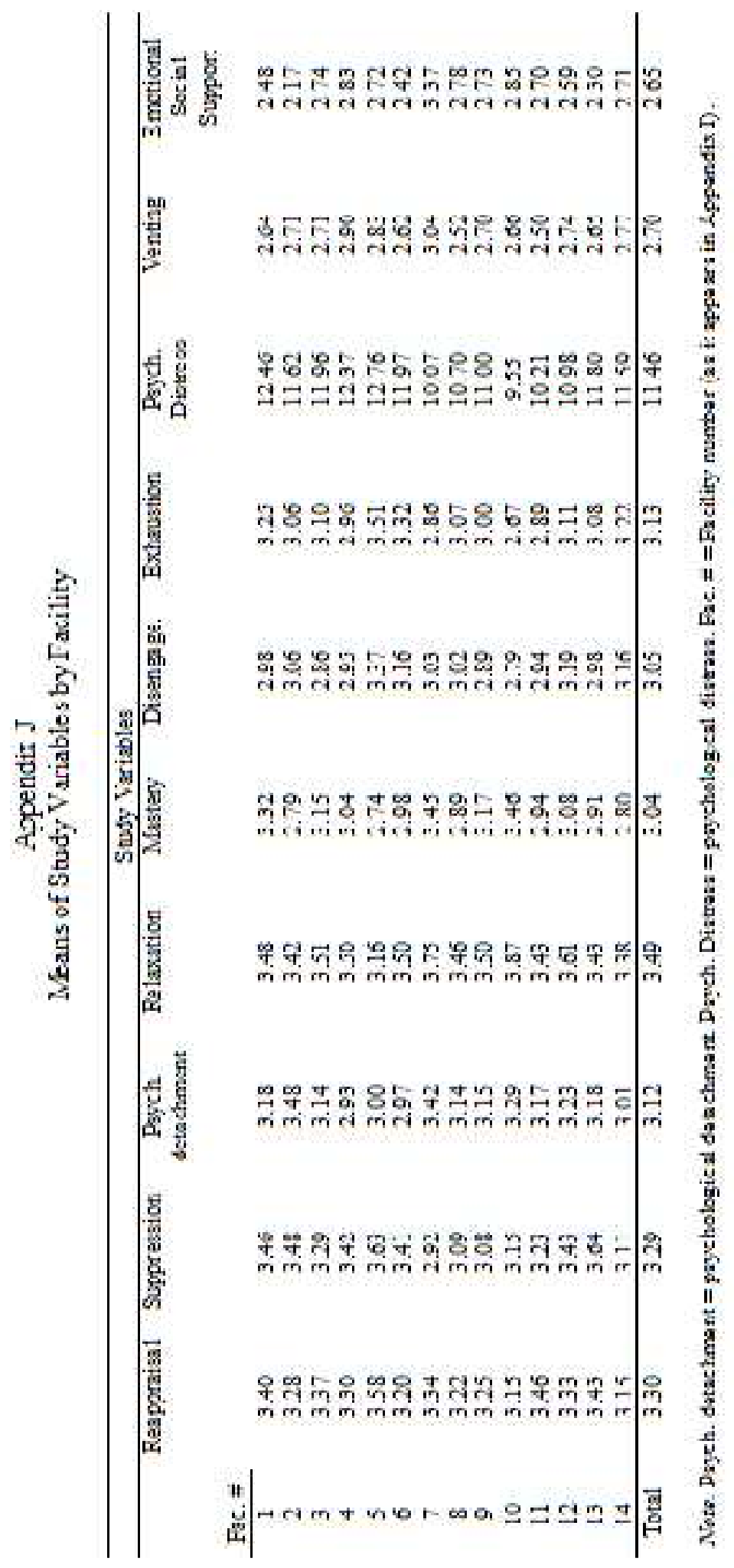

